\title{
Industry 4.0, Disaster Risk Management and Infrastructure Resilience: A Systematic Review and Bibliometric Analysis
}

\author{
Mahyar Habibi Rad*(D, Mohammad Mojtahedi (D) and Michael J. Ostwald (i) \\ School of Built Environment, University of New South Wales, Sydney, NSW 2052, Australia; \\ m.mojtahedi@unsw.edu.au (M.M.); m.ostwald@unsw.edu.au (M.J.O.) \\ * Correspondence: m.habibirad@unsw.edu.au
}

Citation: Habibi Rad, M.; Mojtahedi, M.; Ostwald, M.J. Industry 4.0, Disaster Risk Management and Infrastructure Resilience: A Systematic Review and Bibliometric Analysis. Buildings 2021, 11, 411. https://doi.org/10.3390/ buildings11090411

Academic Editor: Lucio Soibelman

Received: 13 August 2021

Accepted: 11 September 2021

Published: 16 September 2021

Publisher's Note: MDPI stays neutral with regard to jurisdictional claims in published maps and institutional affiliations.

Copyright: (c) 2021 by the authors. Licensee MDPI, Basel, Switzerland. This article is an open access article distributed under the terms and conditions of the Creative Commons Attribution (CC BY) license (https:/ / creativecommons.org/licenses/by/ $4.0 /)$.

\begin{abstract}
The fourth industrial era, known as 'Industry 4.0' (I4.0), aided and abetted by the digital revolution, has attracted increasing attention among scholars and practitioners in the last decade. The adoption of I4.0 principles in Disaster Risk Management (DRM) research and associated industry practices is particularly notable, although its origins, impacts and potential are not well understood. In response to this knowledge gap, this paper conducts a systematic literature review and bibliometric analysis of the application and contribution of I4.0 in DRM. The systematic literature review identified 144 relevant articles and then employed descriptive and content analysis of a focused set of 70 articles published between 2011 and 2021. The results of this review trace the growing trend for adoption of I4.0 tools and techniques in disaster management, and in parallel their influence in resilient infrastructure and digital construction fields. The results are used to identify six dominant clusters of research activity: big data analytics, Internet of Things, prefabrication and modularization, robotics and cyber-physical systems. The research in each cluster is then mapped to the priorities of the Sendai framework for DRR, highlighting the ways it can support this international agenda. Finally, this paper identifies gaps within the literature and discusses possible future research directions for the combination of I4.0 and DRM.
\end{abstract}

Keywords: Industry 4.0; disaster risk management; resilient infrastructure; Sendai framework; prefabrication and modularization; big data analytics; Internet of Things; bibliometric analysis; systematic literature review

\section{Introduction}

In the last decade, there has been a rapid digital transformation of industrial production systems. This has led to more intelligent, flexible, integrated and efficient processes [1-3]. This new paradigm is often called 'Industry 4.0' (I4.0) or 'the 4th industrial revolution' [4,5]. The origins of I4.0 can be traced to a strategy outlined in a governmentfunded report produced in Germany in 2011, to promote competitive advantages of manufacturing through the utilization and integration of new technologies [6]. Since then, I4.0 has been linked to growing digitalization, flexibility, automation, virtualization, resource efficiency and decentralization across all industries [7]. I4.0 combines different technological approaches and models such as Artificial Intelligence (AI), Digital twins, Blockchain and Cloud computing [8] to expedite computerization and interconnectedness in diverse industries, leading to operational excellence [9]. I4.0 technology ('I4 T'), which facilitates the physical processes and information flows in a value chain, can arguably assist organizations to achieve sustainable goals through reduction of lead time, improvement of work environment and quality of products [10].

Effective I4 Ts are considered critical to achieving economic, social, and environmental benefits in multiple industries [11]. For example, healthcare [12], information technology [13] and transportation [14] sectors can, and do, employ I4 T in their daily programs. In particular, the construction industry has adopted I4.0 transformation to achieve more 
efficient production chains and to digitally enhance automated production. As a result, the term 'Construction 4.0 ' has been used to describe the digitalization of the construction sector. At the core of Construction 4.0 is performance optimization and project performance simulation using Building Information Modelling (BIM) to integrate all project in-formation throughout the project's lifecycle, from the initial stage of design to construction, operation, maintenance and delivery [15]. In a similar way, the use of Digital Twin (DT) technology has become more extensive in some industries, especially manufacturing, where the entire product lifecycle-from design to delivery stage, to monitor progress, optimize performance, simulate the results, and foresee possible errors—can be accommodated [16].

A further factor shaping the growth of I4.0 in construction is its capacity to support the Lean Production paradigm. Lean is the most extensive production paradigm nowadays, as it seeks to reduce non-value-added activities in the whole process of production [17]. Academics and practitioners have identified Lean principles as a prerequisite of I4.0 implementation, and proposed that $\mathrm{I} 4 \mathrm{~T}$ is a means of overcoming Lean production constraints and improving its practices [18]. As such, the combination of I4 $\mathrm{T}$ and Lean can be linked to performance improvement, increasing flexibility, productivity and quality, and reducing the delivery time and cost of projects $[19,20]$.

In parallel with these developments in I4.0, Construction 4.0 and I4 T, an unexpected connection has become evident to a further field. Disaster risk scientists and the humanitarian sector were encouraged by the Sendai framework for Disaster Risk Reduction (DRR) to invest in the development of advanced innovative technologies in Disaster Risk Management (DRM) to cope with the numerous challenges that occur in the disaster recovery life cycle [21]. Izumi et al. [22] conducted a survey of disaster management practitioners, drawn from academia, government and the private sector, to pinpoint the most efficient DRR approaches and tools in DRM. They found that innovative community-based disaster risk reduction tools are the most effective to assist in reducing risk. Meanwhile, the implementation of Artificial intelligence (AI) and communication tools associated with disaster recovery, have been proposed to enhance contemporary strategies and capabilities for DRR. Similarly, Ogie et al. [23] systematically reviewed the application of machine learning techniques and $\mathrm{AI}$ in disaster communication tools. Their findings reveal the capacity of AI to predict and monitor multi-hazard early warning systems and information extraction for situational awareness.

Against this background, it is perhaps not surprising that a confluence of ideas has begun to occur around the combination of I4.0, I4 T, Construction 4.0 and disaster management. The built environment has experienced unprecedented disasters in the last decade, having an immense impact on societies and economies [24-27]. Such disasters highlight the need for innovative tools and technologies to support the DRM process. The tools being considered appear to draw freely from those developed in I4.0, adopting ideas from Construction 4.0, and concepts from several related fields. The rapid development of knowledge in this combined field has led to a growing need to understand its context, framing and conditions.

It is not surprising, in a field that is rapidly evolving and drawing on multiple new methods, that there are fundamental research gaps which need addressing. Possibly, the most urgent need is to respond to the lack of research which considers the integration of the findings of previous studies pertinent to the implementation of Industry 4.0 technologies in the context of disaster risk management. There is a tendency in the literature for researchers to non-critically assume that isolated findings in past research are translatable to new disciplinary contexts. A systematic literature review is one way of beginning to address this deficiency. While it cannot resolve all the knowledge gaps, or the translation of all ideas across disciplines, it does contribute to the identification, classification and presentation of the holistic and critical overview of preceding studies. As such, this paper proposes a systematic literature review of I4 $\mathrm{T}$ in disaster science. This review is intended to contribute to the development of this field and answer the following research questions:

RQ1: What trends are identifiable in the adaptation of I4 T in the DRM area? 
RQ2: How does research suggest that the implementation of I4.0's digital agenda contributes to enhancing the DRM cycle?

This paper is constructed in five sections as follows. Section 2 presents the research methodology. Section 3 outlines the findings and results for the first question explored in this paper. Section 4 discusses key points identified in the review to address the second research question, and it also maps the findings to the priorities of the Sendai framework for DRR. Finally, Section 5 presents the results and concluding remarks.

\section{Research Methodology}

A systematic literature review (SLR) is used in this paper to investigate research relating to I4.0 and DRM. An SLR is a comprehensive research method that applies pre-planned strategies to review past research using a structured analysis-synthesis procedure [28]. This method is used to answer particular research questions based on current studies, to choose and assess contributions, examine and synthesize data and present evidence in a way that empowers the investigator to draw rigorous conclusion [29]. An SLR requires the following stages: (1) question formulation; (2) localization and searching the literature; (3) study selection and evaluation; (4) analysis and synthesis; and (5) reporting and interpretation of results. Figure 1 presents a summary of the process applied in the present research.
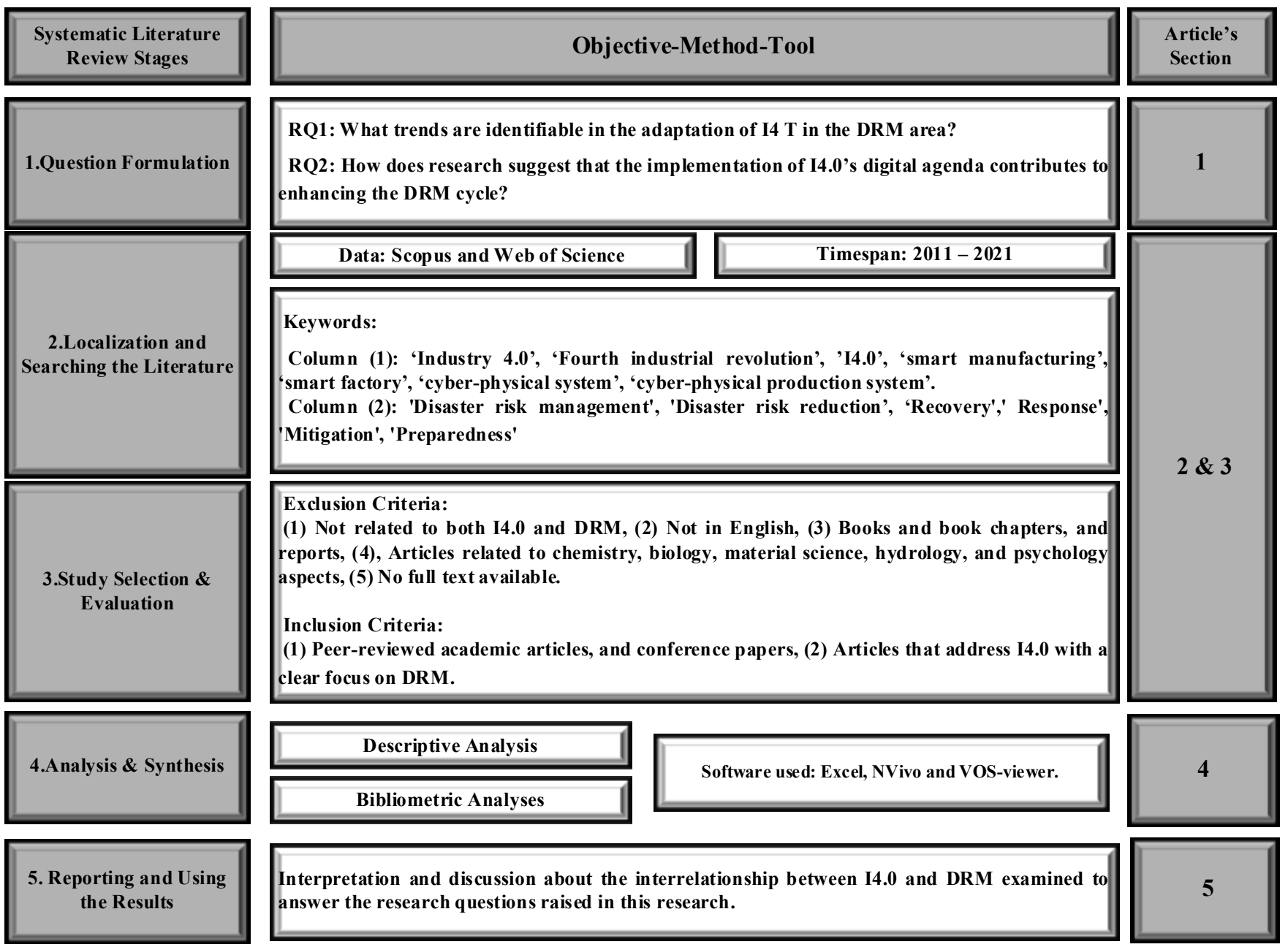

RQ1: What trends are identifiable in the adaptation of $\mathrm{I} 4 \mathrm{~T}$ in the DRM area?

RQ2: How does research suggest that the implementation of I4.0's digital agenda contributes to enhancing the DRM cycle?

Data: Scopus and Web of Science

Timespan: $2011-2021$

Keywords:

Column (1): 'Industry 4.0', 'Fourth industrial revolution', 'I4.0', 'smart manufacturing', smart factory', 'cyber-physical system', 'cyber-physical production system'.

Column (2): 'Disaster risk management', 'Disaster risk reduction', 'Recovery',' Response', Mitigation', 'Preparedness'

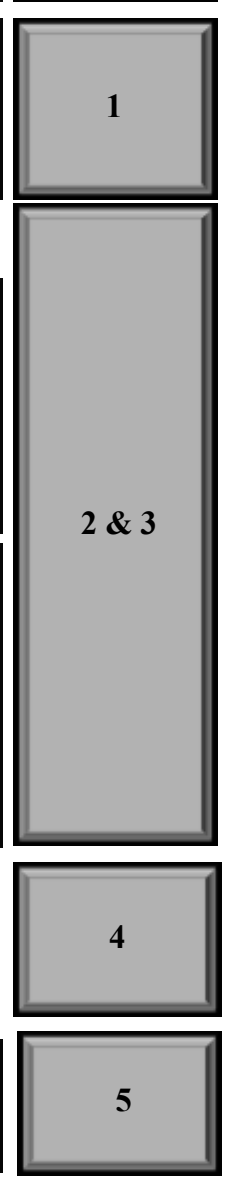

Figure 1. Summary of the systematic literature review stages and processes adapted from Garza-Reyes [30]. 
The first stage is associated with formulating research questions to assist in achieving the objectives of the systematic literature review. The second stage is related to specifying the source's location for searching the literature. The chosen sources were Scopus and Web of Science. These sources are commonly used multidisciplinary online academic databases encompassing publications from selected peer-reviewed journals, books and conference proceedings. Opinions about these data-bases vary, with Wang and Waltman [31] arguing that, in terms of the accuracy of the journal classification system, Web of Science works are considerably better than those of Scopus, while Martín-Martín et al. [32] contend that Scopus is preferred. This paper uses both the Web of Science and Scopus databases, coupled with Google Scholar as an additional check.

The time span selected for review was from 2011 to June 2021. The starting point for this study was chosen to reflect the fact that the concept of 'Industry 4.0 ' was used for the first time in 2011 [33].

For a rigorous application of the SLR method, keywords must be chosen with great care. The selected keywords and search terms were classified into two sets, 'column (1)' and 'column (2)'. Column (1) has keywords associated with I4.0 and its synonyms: 'I4.0', 'Fourth industrial revolution', 'smart manufacturing', 'smart factory', 'cyber-physical production system' and 'cyber-physical system'. Column (2) contains the most frequent keywords associated with DRR, and its four-stage cycle: 'recovery', 'response', 'mitigation' and 'preparedness'.

The search process was conducted independently, term by term, where the words in column (1) were individually combined with column (2) words. For instance, the combined sets of keywords were ('Industry 4.0' and 'Disaster risk management'); ('Industry 4.0' and 'Disaster risk reduction'); ('Industry 4.0' and 'Recovery') and continued consecutively to the final set ('cyber-physical production system' and 'Preparedness'). The search terms used were sufficiently broad not to limit the search, while targeted enough to address the objectives of this study. Subsequently, the selection of articles was also restricted to the title, abstract and keywords, these being determinant factors in the collection procedure.

The third stage, study selection and quality evaluation, is linked to the inclusion/exclusion criteria and applied classification procedure. The exclusion criteria were designed around the fundamental concepts and approaches of I4.0 and DRM. Papers lacking coverage of both concepts were excluded. Those articles that did not clearly focus on the topic of DRM and I4.0 (e.g., by discussing I4.0 in the context of hydrology, chemistry or psychology) were eliminated. Only articles in English and with full text available were considered in this research. This was to ensure that comprehensive content analysis could be used to find to what extent, and how, the papers contributed to the two research questions identified for this study. The inclusion criteria provided additional assistance for the selection procedure. Thus, research findings only included peer-reviewed academic articles and the proceedings of international conferences papers, as Saunders et al. [34] claim that these sources are the most reliable for conducting literature reviews.

Data analysis and synthesis were carried out in the fourth stage using the content analysis techniques of White and Marsh [35]. Using the criteria outlined in this section, a final sample of 70 papers was identified and uploaded to Excel software. Then, selected articles were categorised based on year/citation of publication, research methods applied in the articles, sector classification and country of origin, to provide a clear understanding of the past research carried out in this field. The results were uploaded to NVivo and VOSviewer software to conduct a qualitative literature synthesis and bibliometric synthesis.

Finally, the collected data-about the interrelationship between I4.0 and DRM-was examined to respond to the research questions raised in this paper.

All five stages are compiled in Figure 2 by applying the Preferred Reporting Items for Systematic reviews and Meta-Analysis (PRISMA) flow diagram of Moher et al. [28]. From the initial 547 documents identified through database searching, 144 were considered for general analysis and 70 were identified as relevant for detailed analysis to answer the first research question. This selection process follows the stages recommended by 
Liberati et al. [36] (Figure 2), involving: (a) the identification of the papers; (b) screening; (c) classification; and (d) analysis.
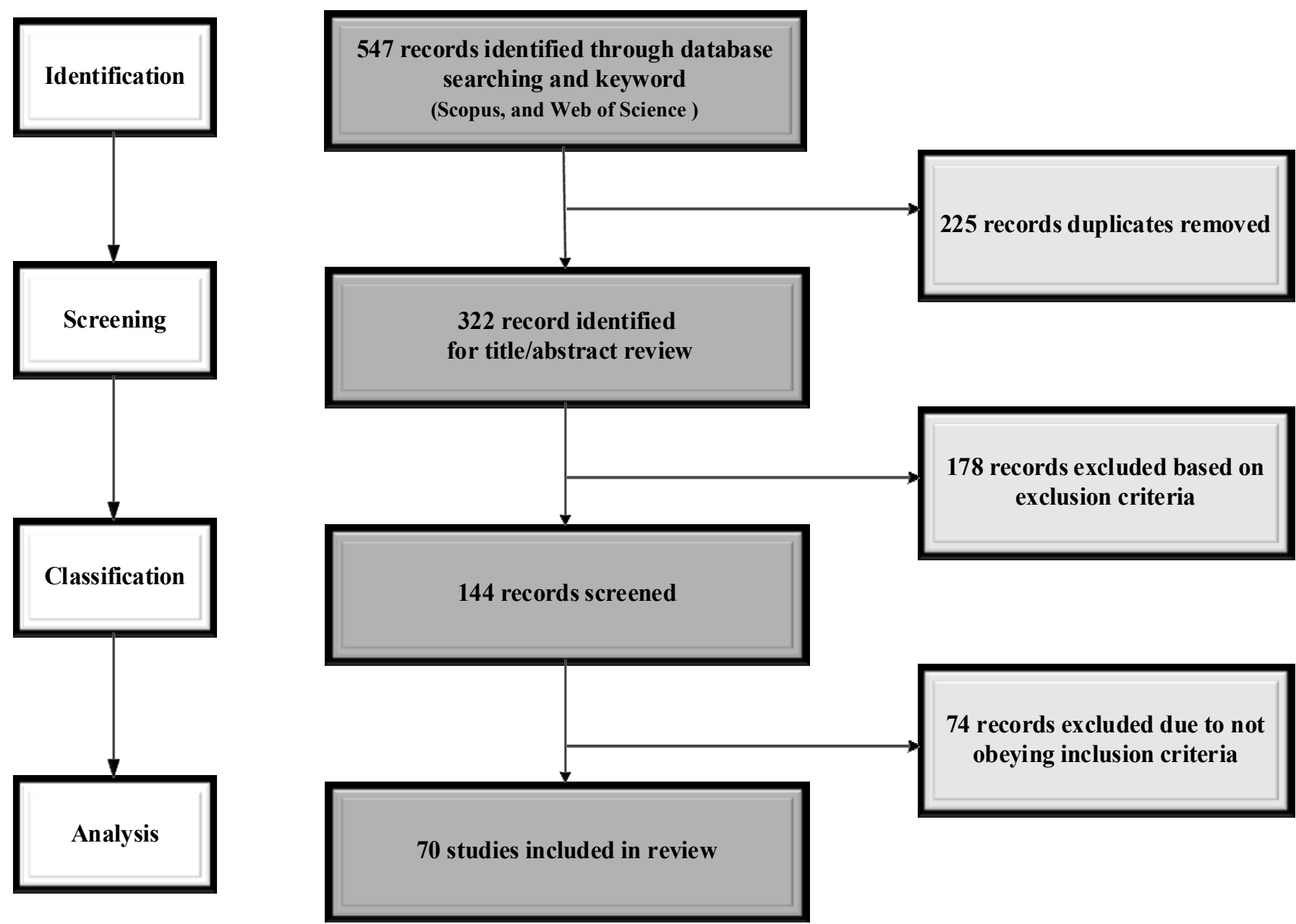

Figure 2. PRISMA flowchart with the process applied in this research.

\section{Results}

\subsection{Descriptive Analysis of Results}

Based on the selection criteria stated in the preceding section, 70 articles meeting the inclusion and exclusion criteria were identified. Consequently, this section presents an overview of these articles. Thereafter, content analysis is conducted to consider I4 $\mathrm{T}$ in DRM, and to answer the two research questions.

\subsubsection{Sources and Number of Articles per Year}

It is clear in the data that the concept of combining I4.0 or I4 T and disaster management is gaining momentum [8], offering a new means of dealing with the social and economic destruction caused by catastrophes around the globe [37]. Figure 3 shows the number of articles and citations by year, demonstrating the rapid growth of this field since 2016. The number of articles has doubled each year since 2018 . Indeed, over $90 \%$ (64) of eligible papers were published after 2018, indicating an exponential growth in I4.0-Disaster related studies. While only six articles relevant to this domain published by 2019 , considerable growth in the number of publications is evident. While only six articles relevant to this domain were published by 2019, a considerable growth in the number of publications is noticeable. Although the number of publications reaches a peak in 2020, a decline in the 2021 publications is evident, which could be explained by the unavailability 
of future publications in this year. The figure also reveals that the number of citations increased from 2016 onwards, with a distinct rise 2019 signalling an increasing interest in utilizing digital technologies in DRM. This might be due to the benefits obtained from implementing I4 $\mathrm{T}$ and digitalization across various sectors. The mean number of citations per paper (23) published in the selected papers is significantly higher than the median citation per year (6). The result indicates that an increase in the number of citations is not an individual reflection of the rise in the volume of publications. Projections from this data suggest a growing trend in the number of publications after 2021.

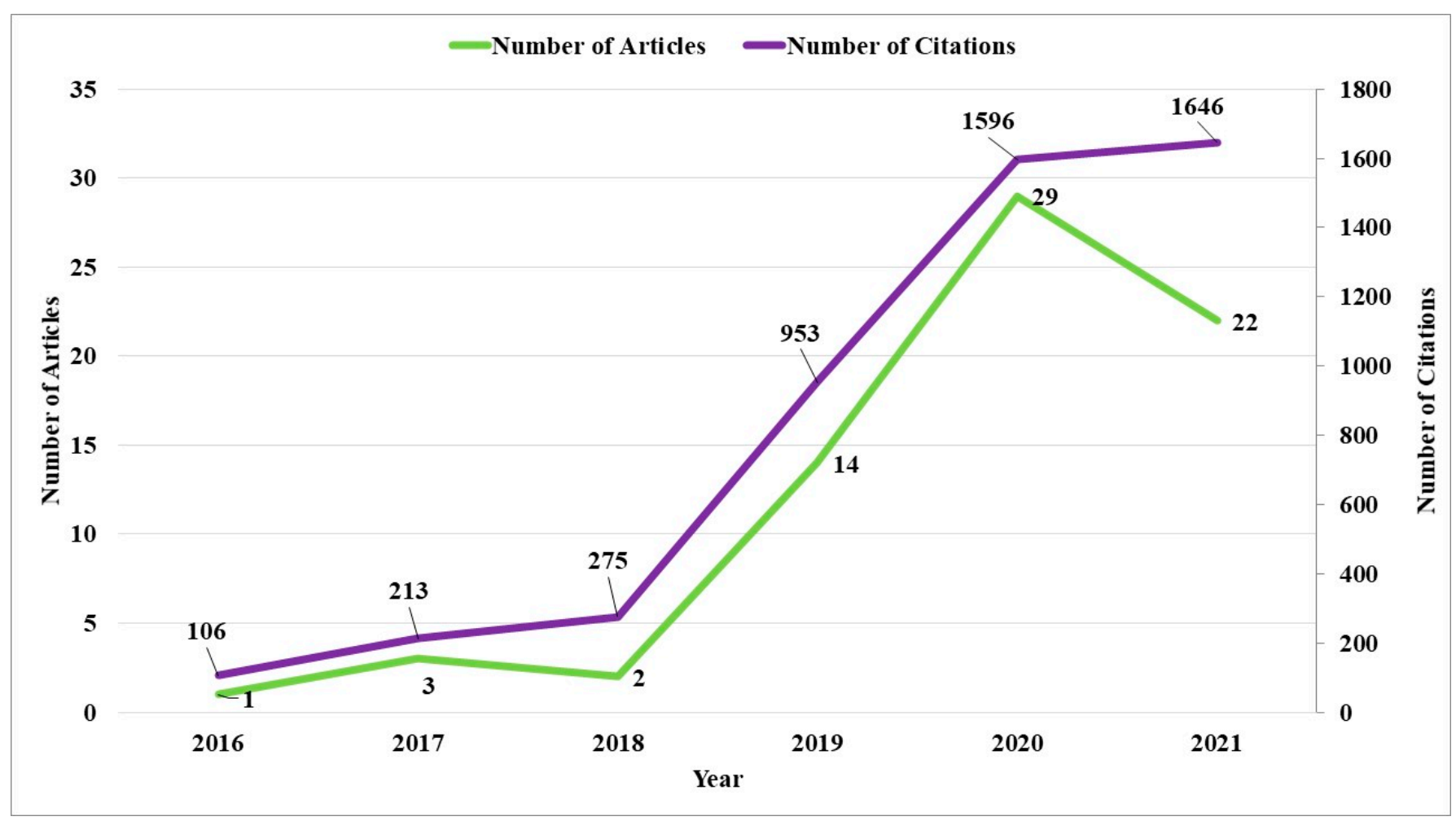

Figure 3. Number of publications/citations studied per year.

\subsubsection{Research Methods Applied in the Articles}

Figure 4 shows the research methods used in the 70 publications. The primary form of analysis identified is qualitative, using a subjective viewpoint and without quantifiable data. Approximately 55\% (39) of all articles used a qualitative method. In contrast, quantitative analysis (the presentation of a mathematical and statistical approach to comprehension and prediction) was only used in 13\% (9) of the articles. Qualitative methods pro-vide scholars with a rich resource of contextual data, not readily available in quantitative research [38]. However, irrespective of intent and endeavour, the volume of subjective studies could be regarded as a limitation in past research. Conversely, data gathering and analysis using quantitative methods are more straightforward, although they too have their limitations [39]. Nevertheless, prima facie, this data suggests the need for more quantitative studies in the future. Almost 19\% (13) of all papers used computational analysis (the use of computer techniques to assess data), while a mixed method (combination of quantitative and qualitative approaches) was found in about 13\% (9) of all articles. This reinforces a potential need for additional quantitative methods to enhance the DRM cycle by implementing I4.0 concepts and I4 Ts. 
45

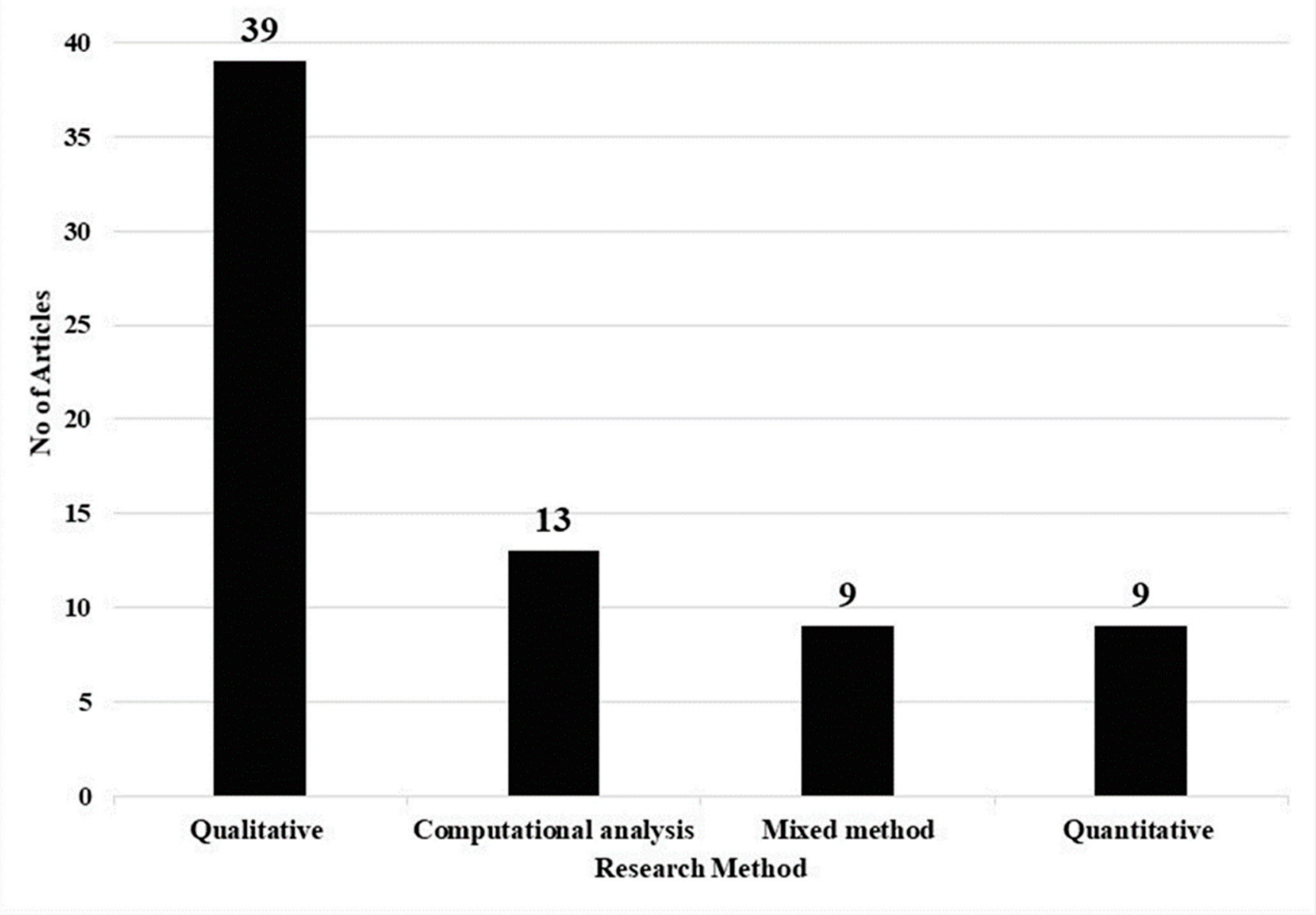

Figure 4. Research methods applied in the articles.

\subsubsection{Sectoral Analysis of Findings}

This section reports the findings by sectoral classification (Figure 5). Research on the use of I4.0 and digitalization has gained significant moment in the last decade [8]. Consequently, several sectors have sought to adopt these approaches to find innovative ways of considering disruption risk control analytics. According to Dalenogare et al. [2], I4.0 technologies, by integrating manufacturing processes and increasing product connectivity, can help manufacturing companies attain a higher level of industrial performance. The growing interest in the manufacturing sector for achieving the anticipated benefits of adopting different I4.0 tools could be seen in the articles published in this sector, as about one-third (31\%) focused on the manufacturing area. The rapid advancement of information technology has also greatly influenced manufacturing systems. This development could also bring about changes in attitudes toward the implementation of various digital technologies across other sectors. The information technology sector is an inevitable part of this process, and it is the second higher sector, with 14 articles (20\%). The construction sector has also played a critical role in disaster recovery projects [40], which can be seen in the publications on this sector (11 publications, 16\%). The transportation sector has $9 \%$ of all articles, and it could be considered a pioneer in adopting digital technologies leading to resilient smart infrastructure. Research has also been conducted on the humanitarian and disaster operation sector [37], public health [41] and energy sector [42]. Despite the importance of the humanitarian sector, findings highlight that only $5 \%$ of all articles were focused on this area, suggesting a potential gap in past research or future research opportunities. 
25

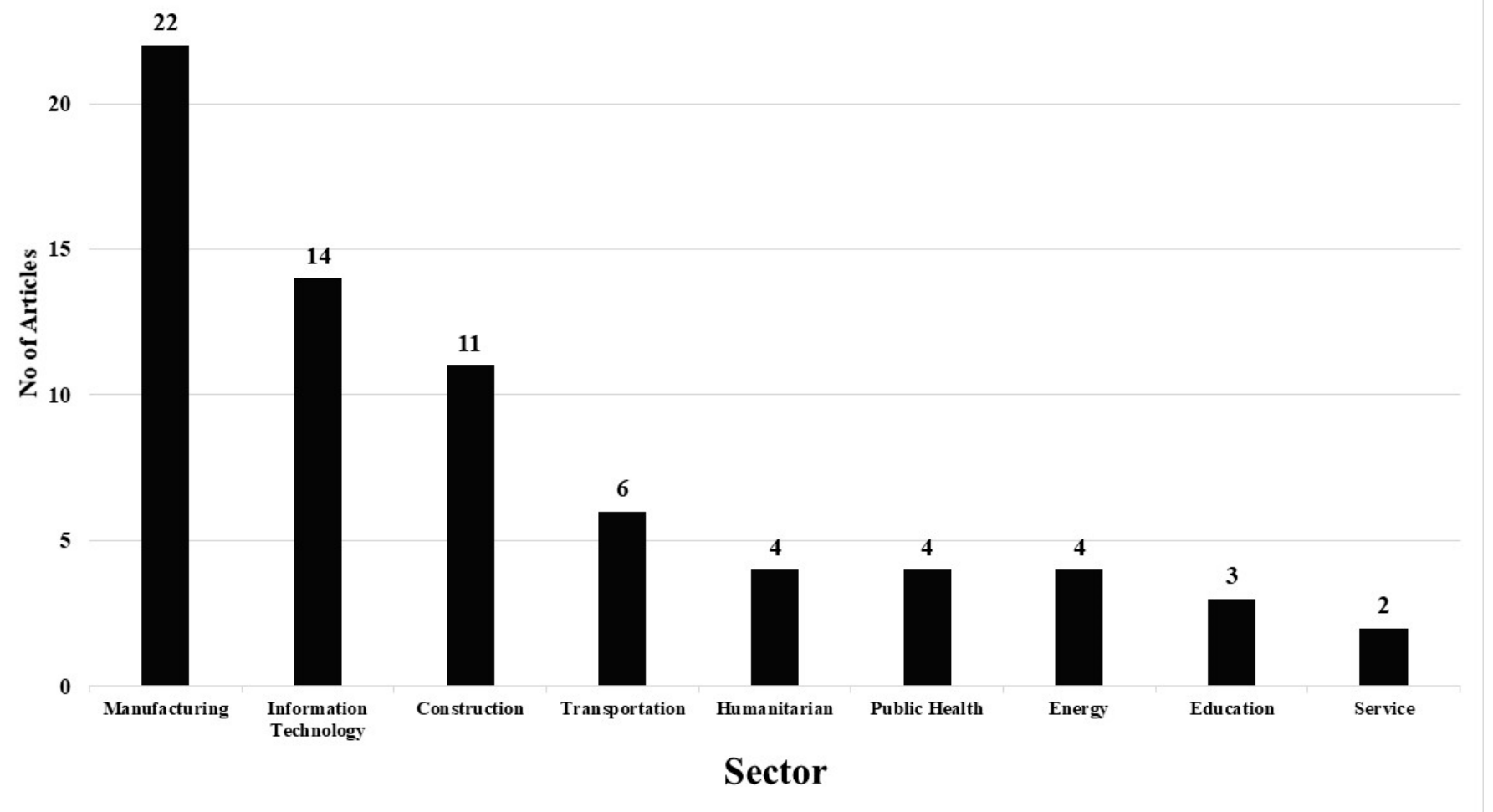

Figure 5. Number of articles by sector.

\subsubsection{Analysis of Findings by Country of Origin}

Figure 6 illustrates the articles classified by the 20 countries of origin: Australia, Brazil, China, France, Germany, India, Iran, Ireland, Lebanon, Malaysia, Pakistan, Philippines, Poland, Russia, Singapore, United Kingdom, Turkey, Spain, Taiwan, and the United States. This diverse geographic distribution suggests a global interest in digital tools in DRM. Articles from the United States (15) are at the forefront of this new field, followed by articles from India (11), China (9) and Germany (7). These results, while still relatively small numbers, emphasize the role of developed countries in driving the development of the I4.0 phenomenon and incorporating these tools and technologies into DRM practices. This trend might derive from the demand in these countries to mitigate the impact of disruption caused by the catastrophes on their urban infrastructure networks.

\subsection{Bibliometric and Content Analyses}

Bibliometric analysis covers a wide range of research, including identifying cooccurrence, keyword mapping, citation analysis, authors analysis, and analysis of countries for their impacts on the subject field of the SLR [43]. This methodology is renowned for presenting a broad review of a theme of interest, defining its frontiers and proposing unbiased agendas for prospective research [44]. Previous studies have used this method to establish intellectual structures of research subjects in varied areas, such as sustainability [45], business management [46] and manufacturing [47]. The present study conducted a co-occurrence and word cloud analysis of keywords, to determine the central research clusters associated with I4.0 and disaster management. A two-stage analysis was carried out. The first stage was conducted based on the 144 records screened in (PRISMA) flow diagram to systematically review literature (see Figure 7) and present a general viewpoint about the research topic. Then, the second stage was used to identify distinct clusters, based on the 70 selected articles that ultimately met all inclusion/exclusion criteria (see Figure 9). 


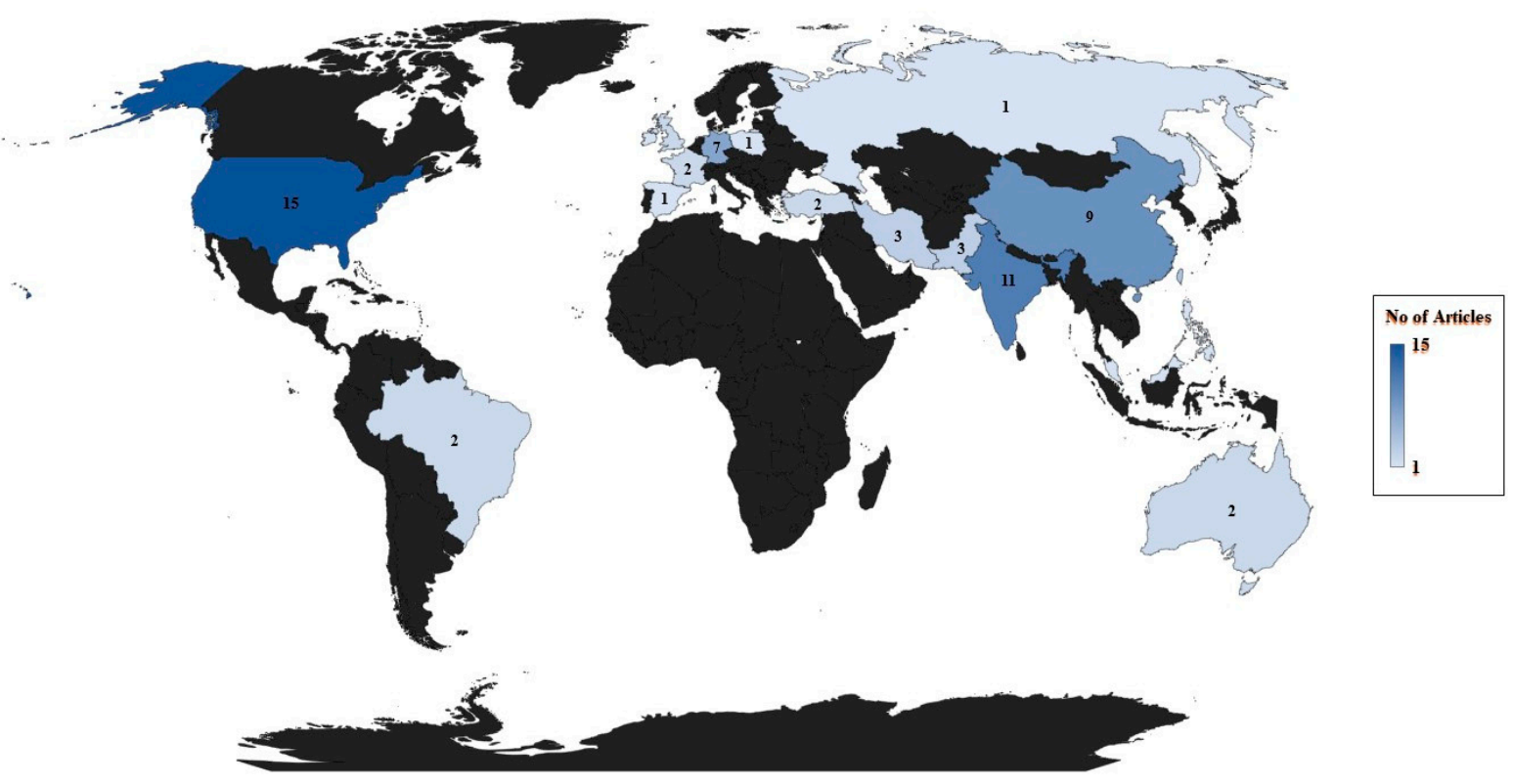

Figure 6. Articles classified by country of origin.

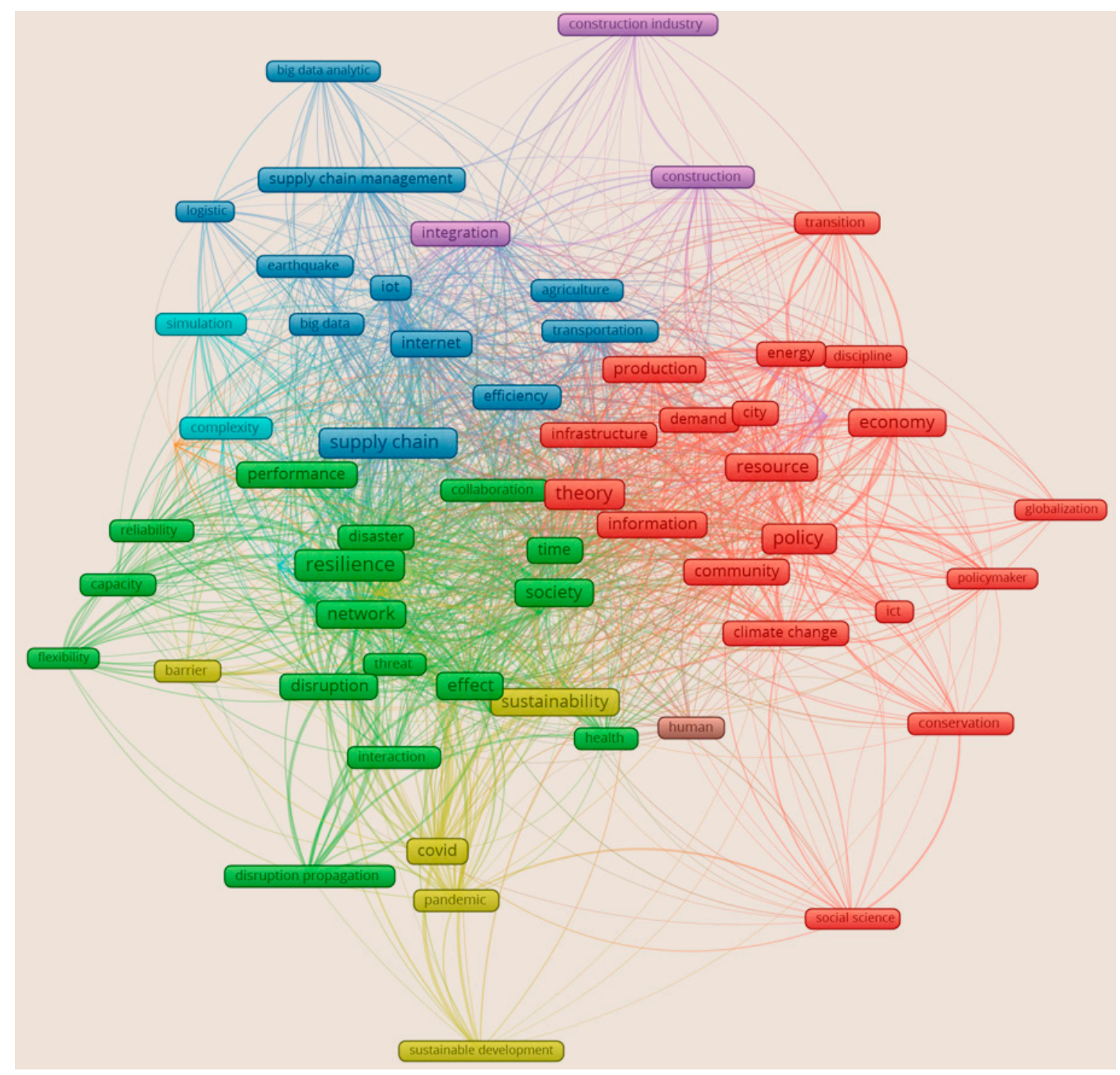

Figure 7. Co-occurrence analytical map of keywords established by bibliographic analysis of the 144 retrieved articles. 
A large number of software packages can be used for this process, such as VOSviewer [48], Gephi [49], Bibexcel [50] and CiteSpace [51]. The present study employed VOSviewer to conduct bibliographic analysis and co-word analysis. This decision was due to the software's capability to present a wide range of data visualizations and its appropriateness in investigating large datasets. NVivo software was used to establish word clouds of keywords, due to its efficiency in coding data from full articles [52].

\subsubsection{Co-Occurrence Analytical Map and Word Clouds Analysis of Keywords}

The co-occurrence analytical map was generated by applying bibliographic analysis of the selected articles to examine the major keywords and topics employed in the identified I4.0 and DRM records (Figure 7). Because this type of data synthesis does not deliver indepth insights into the literature [53], content analysis was also carried out. Furthermore, the word cloud of 144 selected abstracts records was established to validate the results derived from the co-occurrence analytical map of keywords (Figure 8). Finally, the content of the articles in each cluster was reviewed.

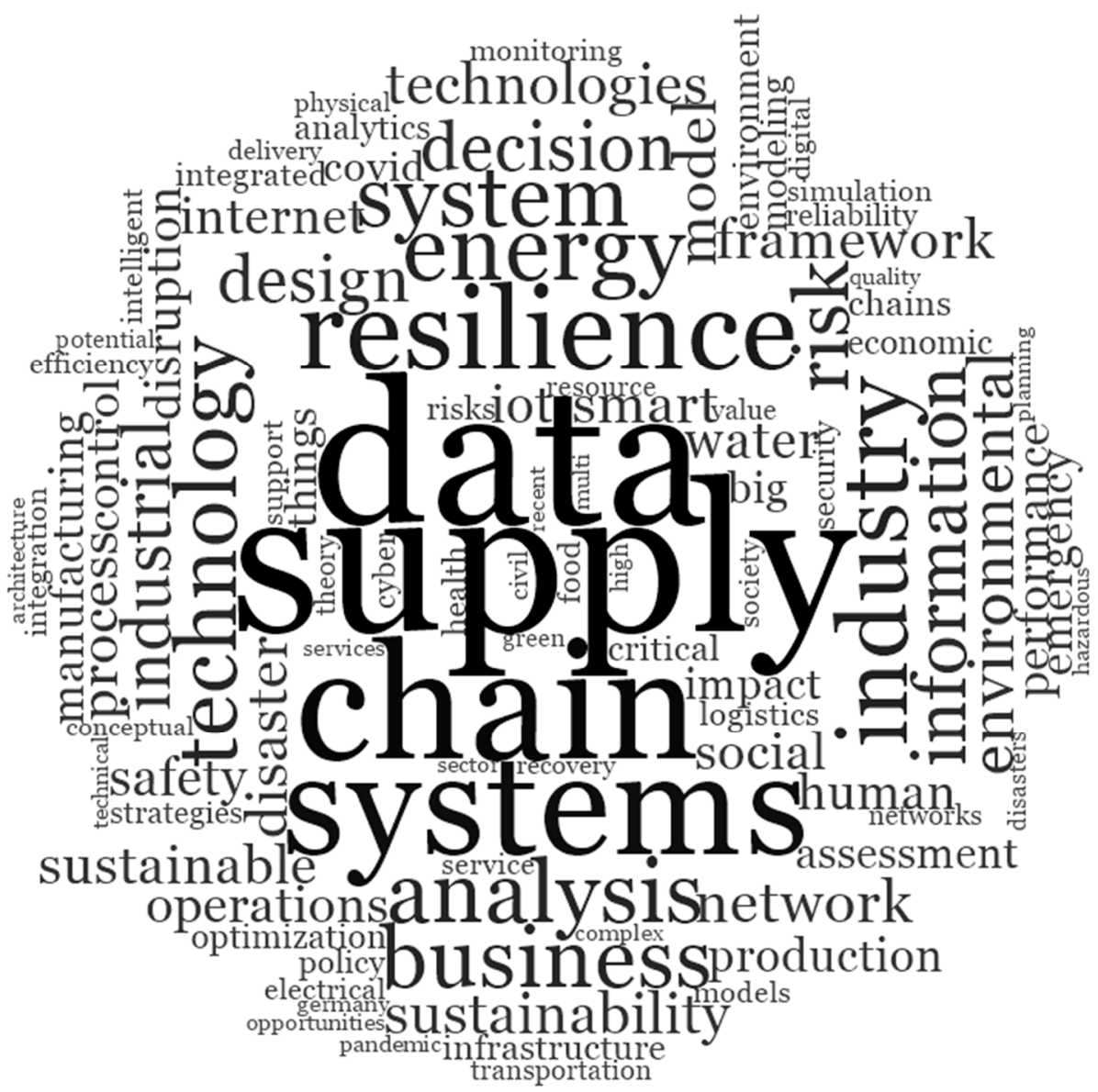

Figure 8. Word clouds of the preliminary clusters based on 144 retrieved articles.

Co-word analysis, being the level of co-occurrence of keywords, helps researchers visualize a set of publications' core content [54]. Figure 7 is the co-occurrence analytical map established for the present study. The coloured groupings of nodes' size indicate the volume of publications that contain the particular keywords-therefore, the larger the coloured group, the more extensive the body of knowledge in that area. Previous researches have argued that combining co-word analysis with word clouds may provide a more profound understanding of a research topic's development and intellectual structure, as these two techniques complement each other [43,53]. Thus, Figure 8 emphasizes, perhaps more clearly than Figure 7, that the main focus is on supply chain and system analysis, 
followed by energy, resilience and business. While less clear in Figure 7, the supply chain is the most referenced cluster (blue). It is also worth noting that a certain degree of instability may be inherent in the results from this analysis due to the evolution in key terms over the years [54].

Figure 9 is the co-occurrence map of keywords in the core set of 70 articles. Six clusters in the literature are identified in Figure 9: AI; big data analytics; Internet of Things; prefabrication and modularization; robotics; and cyber physical systems. Based on the contribution analysis of I4.0-DRM literature for various domains, the word cloud for the six most researched fields is presented in Figure 10, indicating that the most repeated word is resilience which in line with the results released from the co-occurrence analytical map of keywords. Other most repeated keywords such as information technology, risk analysis, technology disruption and control systems are overall ideas and focus of the studies that could provide further research streams for future studies.

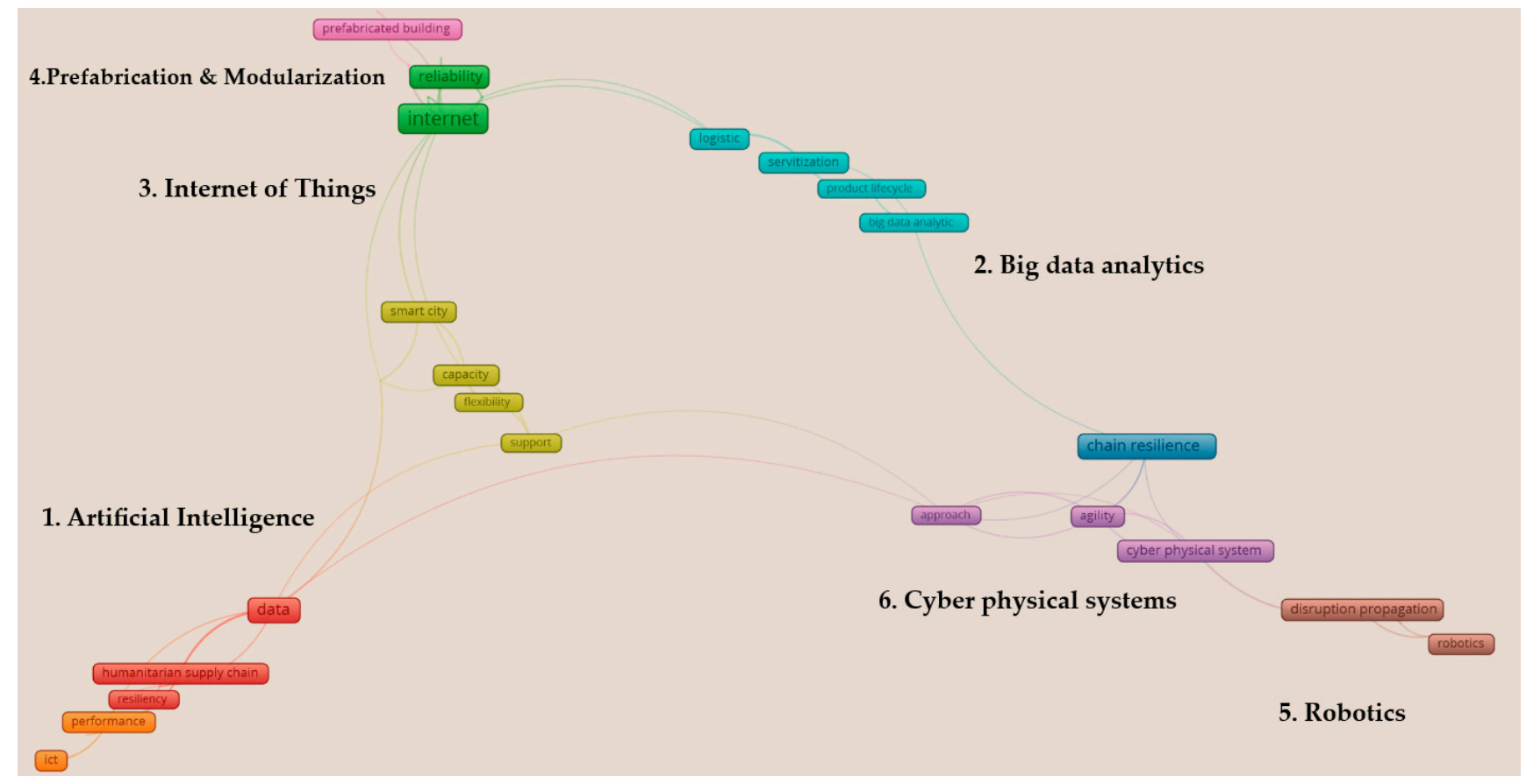

Figure 9. Co-occurrence analytical map of keywords created using bibliographic analysis of the 70 retrieved articles.

\subsubsection{Clustering and Content Analysis}

The focused set of 70 articles was analysed and categorised based upon keyword similarity, creating six clusters (Table 1). The clusters are numbered based on their size, not the order of their emergence. The articles within each cluster were categorised in association with I4.0 and the particular digital tools application in DRM. The clusters, which replicate those in the larger set of 70 articles, are: AI; big data analytics; Internet of Things; prefabrication and modularization; robotics; and cyber-physical systems. 


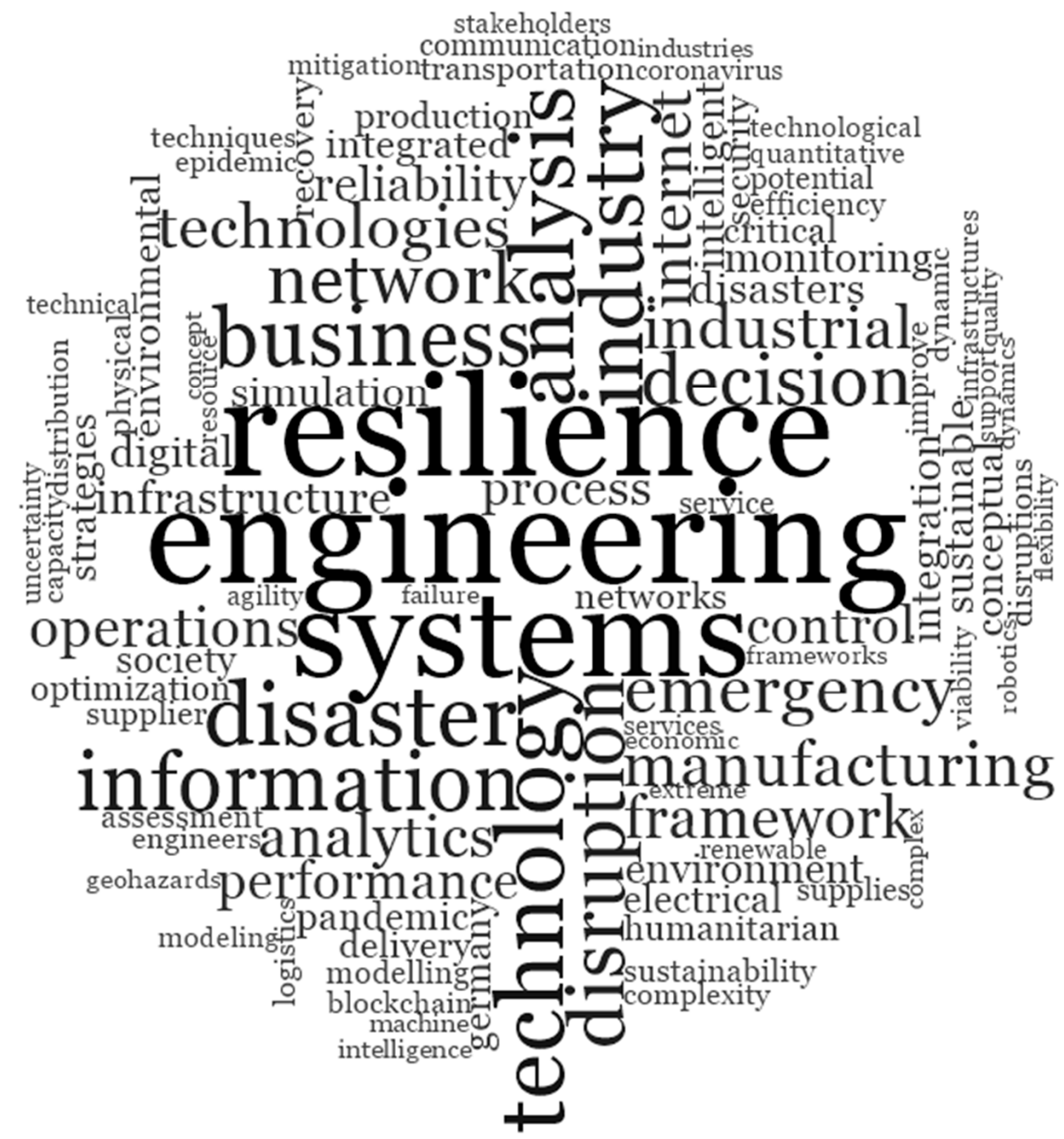

Figure 10. Word clouds of the final clusters based on 70 retrieved articles.

Table 1. Literature classification from co-citation analysis.

\begin{tabular}{ccc}
\hline Cluster & Thematic Area & Articles \\
\hline Cluster 1 & Artificial Intelligence & {$[23,55-64]$} \\
Cluster 2 & Big data analytics & {$[65-73]$} \\
Cluster 3 & Internet of Things & {$[74-82]$} \\
Cluster 4 & Prefabrication \& Modularization & {$[83-87]$} \\
Cluster 5 & Robotics & {$[12,88-90]$} \\
Cluster 6 & Cyber physical systems & {$[14,91-93]$} \\
\hline
\end{tabular}

\section{Discussion}

The present paper raises two research questions. The first asks about trends connecting I4.0 and DRM. To answer this question, we used diverse content analysis and biblio-metric techniques to distinguish the critical domain in the research context. As a result, six clusters are identified showing both the trends and their relative strengths. To answer the second question, this section discusses the contribution of the six clusters of I4.0 tools in the context of DRM. 


\subsection{Artificial Intelligence}

The standard model of disaster management has four stages: mitigation, preparedness, response and recovery. These correspond to activities that occur before and after a disaster, to reduce impacts, save lives and facilitate response and rescue operations. The latter would include preparation for evacuations and reconstruction activities to prepare the community and built environment against future disasters [94,95]. Applying advanced technologies to cope with challenges in disaster management has been encouraged by the Sendai framework for DRR [21]. Disaster management aims to execute operations and strategies to prepare efficiently, respond quickly and rescue, effectively allocate resources, rectify damages, recover functionality, protect the community and limit the adverse consequence of disasters [56]. AI has been applied in DRM to identify hazards and risks, assess vulnerabilities, predict potential consequences and develop mitigation strategies [96]. For instance, infrastructure service disruptions due to disasters can be anticipated based on historical data by applying regression models [97]. Moreover, to build resilient infrastructure against disaster, vulnerability can be assessed by using spatial regression models [98]. AI applications in DRM extend far beyond mitigation and can be used in the prepared-ness stage as well, to provide efficient early warning systems and to optimize the evacuation process [23].

Another application of $\mathrm{AI}$ in the disaster response stage involves utilizing communication tools to provide timely and effective support in the decision-making process. Thus, AI-based communication tools are recommended for improving situational awareness and increasing the effectiveness of response endeavours. These tools could provide effective communication among people engaged in relief and rescue efforts [56]. Moreover, in the aftermath of a disaster, recovery efforts could use AI as an assessment tool for measuring the impact on the damaged structure. AI could be applied further to support recovery plans for disaster areas and track the recovery and reconstruction processes [99]. On the other hand, improving the resiliency of infrastructure using AI-based techniques has also attracted attention. For instance, Mottahedi et al. [100] developed a methodology based on the combination of fuzzy set theory and expert judgment to estimate the resilience of critical infrastructure. Likewise, Dick et al. [64] examined the application of deep learning to detect threats on critical infrastructures within the electricity sector. The results of this past research suggest ways that deep learning and machine vision can enhance the resilience of power systems through preventative maintenance.

Despite the examples in this cluster, there are many additional applications of AI that seem to be under-represented or require further research. As a case in point, applications of AI tools in disaster training systems are rarely studied. Likewise, human response simulators could be studied to prepare human resources for disaster conditions. It might be speculated that there are AI implementation challenges associated with shortage of accurate data in the disaster management context. Data accessibility, completeness and ethical issues (collecting accurate data in humanitarian studies) could all be complicating further AI applications.

\subsection{Big Data Analytics}

Big data analytics encompasses both data-intensive approaches and large-scale information processing applications [101]. The evolution of big data tools in recent years has attracted considerable attention as both industry and academia seek efficiencies or competitive advantages through the use of data sets [102,103]. In DRM, as in other fields, big data analytics offers ways of enhancing competitiveness, productivity and innovation [104]. DRM research emphasizes the importance of big data in enhancing resilience, as it plays a significant role in mitigating risks and impacts of natural hazards. It does this by improving the speed and effectiveness of linkages between disaster information and systemic response [67]. Moreover, studies propose employing big data technologies in different phases of disaster management to enhance resilience. Some examples of this are DRM research into geo-graphic information systems [105], social media data [106] and re- 
mote sensing imagery [107]. Significantly, the first priority for the Sendai framework [108], is increasing our understanding of disaster risks through using earth observation and big geospatial data. That framework highlights the value of community engagement in collecting risk data and encourages the development of community-based innovation practices by using geospatial data to enhance resilience.

The execution of big data analytics in disaster management phases relies on heterogeneous data from frequent sources. Social networking sites, weather departments and government agencies are only a few providers of this data. Gathering and analysing the massive volume of data about disaster resilience is challenging for industry and government groups, but it is necessary to make realistic decisions [101]. Some of the challenges facing big data users include lack of transparency regarding the working principle of analytical tools, poor quality of input data and human subjectivity in processing data, leading to erroneous results [43]. Awareness about such challenges highlights the need for future studies about the practical application of big data analytics to DRM. Successful digital transformation hinges critically on a DRM organization's ability to extract value from big data in enhancing the resilience.

\subsection{Internet of Things}

The Internet of Things (IoT) is an innovative paradigm that is increasingly earning attention in industry and academia [109]. The concept of the Internet of Things (IoT) highlights the possibility of connecting a multiplicity of objects, systems and activities using the internet as a platform [110]. The IoT calls for the linking of all things, with everyone at all times and locations, using built-in wireless connection. The IoT premise is not only that it allows easy connection with all surroundings, but it facilitates monitoring and control processes via the internet [111]. There are many proposed benefits of using IoT in disaster management practices, such as better performance monitoring, effective controlling, superior quality assessment, and cost and time reduction [112]. For instance, Al-Turjman [113] proposed a cognitive data delivery framework to address data delivery challenges in large-scale networks under disaster conditions. The result of that research indicates that an IoT-based framework may be able to optimize the current network status. Likewise, IoT implementation could be beneficial in monitoring and early warning of common geohazards involving rockfall, landslides and earthquakes [74]. IoT can significantly alter how DRM processes are executed, resulting in a faster prediction of natural hazards, more accurate response and less expensive decision-making in recovery. DRM organizations can apply AI to data captured with IoT technologies-sensors, detectors, embedded computers, etc., to predict the natural hazard before it happens.

The second priority for action in the Sendai framework [21] was to encourage improved disaster risk governance processes. IoT, by providing an agile environment for effective decision-making, could facilitate the desired disaster risk governance. It has also been argued that IoT can be employed to improve the infrastructure resilience, using remote sensing to make it more robust. For instance, Russell et al. [114] proposed using signal processing to enhance the resilience of the critical infrastructure. Nevertheless, despite these claimed advantages of IoT tools and techniques, employing IoT in an effective and useful way remains challenging. In particular, technical uncertainty and the high risk of working with IoT should be addressed to improve its trustworthiness and acceptability among users [115].

\subsection{Prefabrication and Modularization}

Prefabricated construction, commonly known as 'off-site construction', involves the fabrication and assemblage of construction components in a controlled and equipped work environment before delivering components to the worksite. Prefabrication has become a growing theme in post-disaster recovery projects $[85,116]$. Off-site construction has been employed in reconstruction projects to reduce variability and improve the productivity, quality and safety of recovery projects [117]. This construction method-which aims 
to increase efficiency and minimize construction time and project costs-is required to apply specialized procedures including automated material tracking and quality control of elements in a confined and controlled work environment [118]. In addition to their construction advantages, it has been argued that off-site construction has more significant social and environmental benefits [119].

The third priority in the Sendai framework concentrates on investing in disaster risk reduction for achieving resilience [21]. Central to this priority is encouraging sectors to develop new products and services to assist in reducing disaster risk [108]. Prefabricated construction is one way of dealing with the diverse challenges of disaster sites. Modular construction could provide an affordable and durable alternative for replacing damaged buildings in a timely way and improving community resilience in the aftermath of a disaster [117]. Despite these benefits, the modularized approach has been criticized as pursuing a traditional fragmented subcontracting approach, which lacks effective collaboration between contractors resulting in unfavourable organizational models [120]. These restrictions can impose massive constraints on recovery projects. For instance, Hong et al. [121] report that despite applying prefabrication technology, China's construction industry still lags behind due to the economic concerns of stakeholders involved in the construction process. As such, one direction for future research could be to consider the off-site market's maturity as an indicator of capacity to effectively use advanced prefabrication technologies in disaster recovery projects.

\subsection{Robotics}

In the last decade, robotic technologies have become increasingly common in many aspects of daily life [12]. The application of robotics in disaster management has been proposed to support a wide range of functions [122]. The fourth priority of the Sendai framework urges the development of resilient systems and services for enhancing the disaster management life cycle [21]. The goal is to support a 'build back better' agenda. Robotics could be used in a wide range of recovery activities, including remote inspection and maintenance of infrastructure at height, underwater and underground inspection, repair and maintenance of energy infrastructure and construction and demolition process of damaged infrastructure $[89,123,124]$. Robotics application could also be expanded to the response stages as well; for instance, utilizing robotics in disaster rescue and relief, assist in timely and effective decision-making process [56]. Likewise, construction robots in recovery projects have been used to execute manual processes and take over repeatable procedures, such as assembling segments, prefabrication and demolition. In other words, robots potentially make construction procedures straightforward to shift from low-level resources (e.g., concrete, steel, etc.) into high-level infrastructure. Moreover, robots can be in charge of high-risk tasks in recovery projects to protect operators from work-related accidents and injuries. Therefore, there are several benefits of such robots in recovery projects, including addressing the labour shortages, reducing operation costs, ensuring overall quality, increasing productivity and reducing safety issues [125]. Despite these benefits, the practical adoption of intelligent robotics in disaster management remains limited [88]. Consequently, continued efforts are required to improve robotics usage in disaster management stages by providing the robotic systems with more capabilities and merging them into the various recovery procedures.

\subsection{Cyber Physical Systems}

Cyber-physical systems (CPS) expand the IoT approach by using the information gathered to work directly in the physical world [126]. Lee [127] (p. 363) defined CPS as "integrations of computation with physical processes. Embedded computers and networks monitor and control the physical processes, usually with feedback loops where physical processes affect computations and vice versa". Due to the high number and multifaceted connections among CPSs, disturbances, such as natural hazards, can severely impact their functionality [91]. Building resilience in critical infrastructures for smart 
cities involves considering various kinds of interdependencies, including cyber, physical and social [14]. CPSs are required to be designed in a way to minimize catastrophic and irreversible damages. Thus, a need exists to develop a resilient and sustainable design, operational and managerial approaches for each infrastructure, along with its organizational characteristics [14].

Research suggests that the application of BIM-based cyber-physical systems is growing for the monitoring of infrastructure throughout its operational life cycle. As a case in point, Bonci et al. [128] examined the application of digital models in managing the operation phase of buildings. The results indicate that the digital model could efficiently assist facility managers in making decisions. Similarly, Ying et al. [129] explored the application of BIM-based cyber-physical systems in managing disaster prevention systems. Their findings could facilitate the intelligent monitoring of infrastructure disaster prevention and mitigation. Thus, the implementation of cyber-physical systems in disaster reduction practices could yield efficient disaster management outcomes.

\subsection{Future Research Agenda}

As a result of the present systematic review, and of the new understanding of disaster management demands it develops, a future research agenda is proposed to assist researchers and practitioners in developing the current body of knowledge. Future studies are expected to focus on the key innovations and implications of I4.0 technologies along with their capacity to shift traditional practices to accommodate a smart disaster management agenda. One of the key new knowledge areas required for successfully adopting I4.0 technologies in disaster research areas is understanding the barriers and challenges pertinent to the implementation of these technologies. Thus, further studies are required with a focus on the identification of these barriers. Another research area that requires further investigation is centred on identifying critical success factors of adopting I4.0 technologies in a disaster management context. This study identified six I4 Ts executed in the pre-disaster and post-disaster areas (Figure 11) which provide a valuable starting point. Finally, according to the literature, a large number of I4.0 technologies have the potential to be executed in post-disaster recovery projects, but this potential needs to be better understood. Thus, further research is required to examine technologies which seek to deliver the potential value of digital transformation to the disaster risk agenda.

Fundamentally, research suggests that I4.0 technologies can lead to the improvement of disaster management activities by integrating digitalization, facilitating automation, enhancing flexibility and growing virtualization in different stages of the disaster management cycle. Although 14.0 covers a wide range of technological approaches, this study only examines the implications of dominant areas in the disaster management literature. The findings highlight the importance of Artificial Intelligence, Internet of Things and Big data analytics in the mitigation and preparedness stages of the disaster management cycle. Moreover, the significance of prefabrication and modularization in post-disaster recovery projects is stressed to enhance infrastructure resilience. Furthermore, robotics implications in response stages, as an efficient means for timely and effective disaster rescue and relief processes, are emphasized. Finally, the importance of cyber-physical systems in monitoring progress, optimizing performance and foreseeing possible errors in the recovery stage is underlined. 


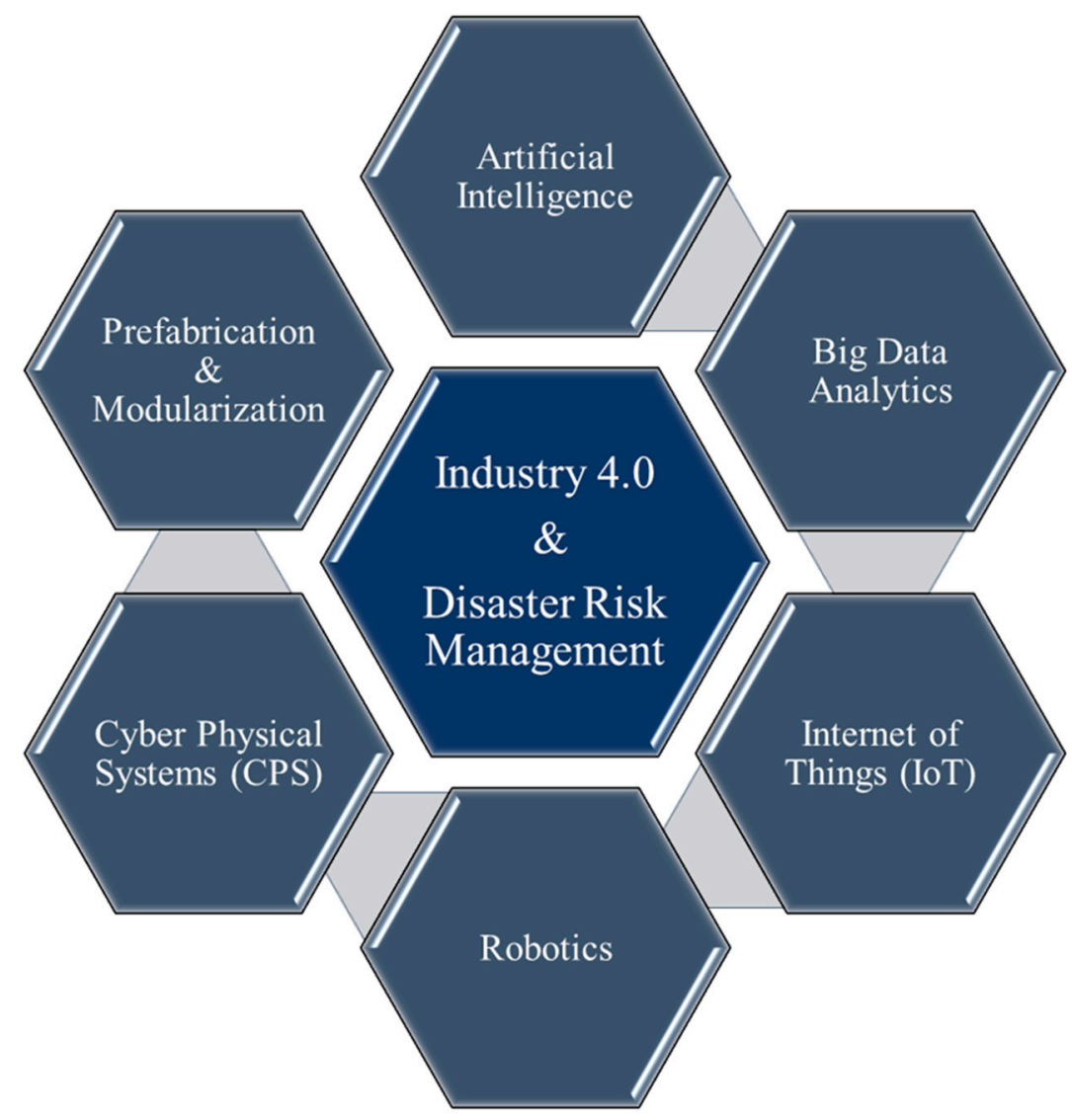

Figure 11. Summary of the findings.

\section{Conclusions}

In this study, we conducted a systematic review and bibliometric analysis of the literature combining I4.0 concepts and tools and DRM. Through a systematic review, an initial set of 144 papers was identified, which was reduced to a focused set of 70 works published between 2011 and June 2021. The SLR method was deliberately chosen to review a large sample size of articles in the disaster research context, improving the reliability of our findings. This review was used to answer two research questions: (1) What trends are identifiable in the adaptation of I4 T in the DRM area? The answer to this question, which is developed through diverse content analysis and bibliometric techniques in Section 3, is six research domains: AI; big data analytics; Internet of Things; prefabrication and modularization; robotics; and cyber-physical systems. (2) How does research suggest that the implementation of I4.0's digital agenda contributes to enhancing the DRM cycle? The answer to this question, which is developed in part 4, is embedded in improving resilient systems and services for enhancing the disaster management life cycle to support a 'build back better' agenda. Also, it is highly notable to consider the Sendai framework for Disaster Risk Reduction as a considerable incentive for developing advanced digital tools and techniques in the disaster risk management domain.

In addition to answering these questions, this paper contributes to the body of knowledge in the I4.0 and DRM field by providing information for practitioners and administrators to information adoption of I4.0 tools in different phases of disaster management. Senior management can use these findings to review the advantages of adopting digital construction tools in recovery projects to execute resilient infrastructure. This study also identified the countries that have carried out the majority of the research in I4.0 and DRM. This can be valuable for government organizations and policymakers in designing their future recovery plans. 
While this review study has been conducted comprehensively, there are two practical limitations. First, the data were gathered from peer-reviewed academic journals and conferences, which excluded the content of master or doctoral theses, unreleased articles and textbooks. The second limitation was the collection of articles from English-language journals only. Therefore, the systematic review did not involve journals in other languages.

Author Contributions: Conceptualization, M.H.R.; methodology, M.H.R.; analysis, M.H.R.; writingoriginal draft preparation, M.H.R.; writing—review and editing, M.H.R., M.M. and M.J.O.; supervision, M.M. and M.J.O. All authors have read and agreed to the published version of the manuscript.

Funding: This research received no external funding.

Institutional Review Board Statement: Not applicable.

Informed Consent Statement: Not applicable.

Data Availability Statement: Data are available from the corresponding author upon written request and subject to review.

Conflicts of Interest: The authors declare no conflict of interest.

\section{References}

1. Lasi, H.; Fettke, P.; Kemper, H.-G.; Feld, T.; Hoffmann, M. Industry 4.0. Bus. Inf. Syst. Eng. 2014, 6, 239-242. [CrossRef]

2. Dalenogare, L.S.; Benitez, G.B.; Ayala, N.F.; Frank, A.G. The expected contribution of Industry 4.0 technologies for industrial performance. Int. J. Prod. Econ. 2018, 204, 383-394. [CrossRef]

3. Vaidya, S.; Ambad, P.; Bhosle, S. Industry 4.0-a glimpse. Procedia Manuf. 2018, 20, 233-238. [CrossRef]

4. Kagermann, H.; Helbig, J.; Hellinger, A.; Wahlster, W. Recommendations for Implementing the Strategic Initiative Industrie 4.0: Securing the Future of German Manufacturing Industry; Final Report of the Industrie 4.0 Working Group; Forschungsunion: Berlin, Germany, 2013.

5. Hermann, M.; Pentek, T.; Otto, B. (Eds.) Design Principles for Industrie 4.0 Scenarios; IEEE: Washington, DC, USA, 2016.

6. Bittencourt, V.L.; Alves, A.C.; Leão, C.P. Industry 4.0 triggered by lean thinking: Insights from a systematic literature review. Int. J. Prod. Res. 2021, 59, 1496-1510. [CrossRef]

7. Luthra, S.; Kumar, A.; Zavadskas, E.K.; Mangla, S.K.; Garza-Reyes, J.A. Industry 4.0 as an enabler of sustainability diffusion in supply chain: An analysis of influential strength of drivers in an emerging economy. Int. J. Prod. Res. 2020, 58, 1505-1521. [CrossRef]

8. Ghobakhloo, M.; Fathi, M.; Iranmanesh, M.; Maroufkhani, P.; Morales, M.E. Industry 4.0 ten years on: A bibliometric and systematic review of concepts, sustainability value drivers, and success determinants. J. Clean. Prod. 2021, 302, 127052. [CrossRef]

9. Luz Tortorella, G.; Cauchick-Miguel, P.A.; Li, W.; Staines, J.; McFarlane, D. What does operational excellence mean in the Fourth Industrial Revolution era? Int. J. Prod. Res. 2021, 1-17. [CrossRef]

10. Kamble, S.; Gunasekaran, A.; Dhone, N.C. Industry 4.0 and lean manufacturing practices for sustainable organisational performance in Indian manufacturing companies. Int. J. Prod. Res. 2020, 58, 1319-1337. [CrossRef]

11. Blunck, E.; Werthmann, H. (Eds.) Industry 4.0-An Opportunity to Realize Sustainable Manufacturing and Its Potential for A Circular Economy; Sveučilište u Dubrovniku: Dubrovnik, Croatia, 2017.

12. Magid, E.; Zakiev, A.; Tsoy, T.; Lavrenov, R.; Rizvanov, A. Automating pandemic mitigation. Adv. Rob. 2021, 35, 1-8. [CrossRef]

13. Sobb, T.; Turnbull, B.; Moustafa, N. Supply chain 4.0: A survey of cyber security challenges, solutions and future directions. Electronics 2020, 9, 1864. [CrossRef]

14. Mohebbi, S.; Zhang, Q.; Wells, E.C.; Zhao, T.; Nguyen, H.; Li, M.; Abdel-Mottaleb, N.; Uddin, S.; Lu, Q.; Wakhungu, M.; et al. Cyber-physical-social interdependencies and organizational resilience: A review of water, transportation, and cyber infrastructure systems and processes. Sustain. Cities Soc. 2020, 62, 102327. [CrossRef]

15. Craveiroa, F.; Duartec, J.P.; Bartoloa, H.; Bartolod, P.J. Additive manufacturing as an enabling technology for digital construction: A perspective on construction 4.0. Sus. Dev. 2019, 4, 251-267. [CrossRef]

16. Lo, C.K.; Chen, C.H.; Zhong, R.Y. A review of digital twin in product design and development. Adv. Eng. Inform. 2021, $48,101297$. [CrossRef]

17. Dieste, M.; Panizzolo, R.; Garza-Reyes, J.A.; Anosike, A. The relationship between lean and environmental performance: Practices and measures. J. Clean. Prod. 2019, 224, 120-131. [CrossRef]

18. Ciano, M.P.; Dallasega, P.; Orzes, G.; Rossi, T. One-to-one relationships between industry 4.0 technologies and lean production techniques: A multiple case study. Int. J. Prod. Res. 2021, 59, 1386-1410. [CrossRef]

19. Habibi Rad, M.; Mojtahedi, M.; Ostwald, M.J. The integration of lean and resilience paradigms: A systematic review identifying current and future research directions. Sustainability 2021, 13, 8893. [CrossRef]

20. Moeuf, A.; Lamouri, S.; Pellerin, R.; Tamayo-Giraldo, S.; Tobon-Valencia, E.; Eburdy, R. Identification of critical success factors, risks and opportunities of Industry 4.0 in SMEs. Int. J. Prod. Res. 2020, 58, 1384-1400. [CrossRef] 
21. UNISDR. Sendai Framework for Disaster Risk Reduction 2015-2030; United Nation: New York, NY, USA, 2015.

22. Izumi, T.; Shaw, R.; Djalante, R.; Ishiwatari, M.; Komino, T. Disaster risk reduction and innovations. Prog. Dis. Sci. 2019, 2, 100033. [CrossRef]

23. Ogie, R.I.; Rho, J.C.; Clarke, R.J. (Eds.) Artificial Intelligence in Disaster Risk Communication: A Systematic Literature Review; IEEE: Washington, DC, USA, 2018.

24. Sarkheil, H.; Habibi Rad, M.; Khorasani, N.A. Measuring water use efficiency and productivity of Tehran using data envelopment analysis. J. Nat. Environ. 2015, 68, 595-608.

25. Ivanov, D. Viable supply chain model: Integrating agility, resilience and sustainability perspectives-lessons from and thinking beyond the COVID-19 pandemic. Ann. Oper. Res. 2020, 1-21. [CrossRef]

26. Benevolenza, M.A.; DeRigne, L. The impact of climate change and natural disasters on vulnerable populations: A systematic review of literature. J. Hum. Behav. Soc. Environ. 2019, 29, 266-281. [CrossRef]

27. Panwar, V.; Sen, S. Economic impact of natural disasters: An empirical re-examination. Margin J. Appl. Econ. Res. 2019, 13, 109-139. [CrossRef]

28. Moher, D.; Liberati, A.; Tetzlaff, J.; Altman, D.G.; Prisma Group. Preferred reporting items for systematic reviews and metaanalyses: The PRISMA statement. PLoS Med. 2009, 6, e1000097. [CrossRef]

29. Tranfield, D.; Denyer, D.; Smart, P. Towards a methodology for developing evidence-informed management knowledge by means of systematic review. Br. J. Manag. 2003, 14, 207-222. [CrossRef]

30. Garza-Reyes, J.A. Lean and green-a systematic review of the state of the art literature. J. Clean. Prod. 2015, 102, 18-29. [CrossRef]

31. Wang, Q.; Waltman, L. Large-scale analysis of the accuracy of the journal classification systems of Web of Science and Scopus. J. Inform. 2016, 10, 347-364. [CrossRef]

32. Martín-Martín, A.; Orduna-Malea, E.; Thelwall, M.; López-Cózar, E.D. Google Scholar, Web of Science, and Scopus: A systematic comparison of citations in 252 subject categories. J. Inform. 2018, 12, 1160-1177. [CrossRef]

33. Bonilla, S.H.; Silva, H.R.O.; Da Terra Silva, M.; Franco Gonçalves, R.; Sacomano, J.B. Industry 4.0 and sustainability implications: A scenario-based analysis of the impacts and challenges. Sustainability 2018, 10, 3740. [CrossRef]

34. Saunders, M.N.K.; Lewis, P.; Thornhill, A. Research Methods for Business Students; Pearson Education: New York, NY, USA, 2015.

35. White, M.D.; Marsh, E.E. Content analysis: A flexible methodology. Libr. Trends 2006, 55, 22-45. [CrossRef]

36. Liberati, A.; Altman, D.G.; Tetzlaff, J.; Mulrow, C.; Gøtzsche, P.C.; Ioannidis, J.P.; Clarke, M.; Devereaux, P.J.; Kleijnen, J.; Moher, D. The PRISMA statement for reporting systematic reviews and meta-analyses of studies that evaluate health care interventions: Explanation and elaboration. J. Clin. Epidemiol. 2009, 62, e1-e34. [CrossRef]

37. AlHinai, Y.S. Disaster management digitally transformed: Exploring the impact and key determinants from the UK national disaster management experience. Int. J. Disaster Risk Reduct. 2020, 51. [CrossRef] [PubMed]

38. Taylor, G.R. Integrating Quantitative and Qualitative Methods in Research; University Press of America: Lanham, MD, USA, 2005.

39. Pearce, A.; Pons, D. Advancing lean management: The missing quantitative approach. Oper. Res. Perspect. 2019, 6, 100114. [CrossRef]

40. Bosher, L.; Dainty, A.; Carrillo, P.; Glass And, J.; Price, A. Integrating disaster risk management into construction: A UK perspective. Build. Res. Inf. 2007, 35, 163-177. [CrossRef]

41. Farooq, M.U.; Hussain, A.; Masood, T.; Habib, M.S. Supply chain operations management in pandemics: A state-of-the-art review inspired by COVID-19. Sustainability 2021, 13, 2504. [CrossRef]

42. Inderwildi, O.; Zhang, C.; Wang, X.; Kraft, M. The impact of intelligent cyber-physical systems on the decarbonization of energy. Energy Environ. Sci. 2020, 13, 744-771. [CrossRef]

43. Khanra, S.; Dhir, A.; Mäntymäki, M. Big data analytics and enterprises: A bibliometric synthesis of the literature. Enterp. Inf. Syst. 2020, 14, 737-768. [CrossRef]

44. Emrouznejad, A.; Marra, M. The state of the art development of AHP (1979-2017): A literature review with a social network analysis. Int. J. Prod. Res. 2017, 55, 6653-6675. [CrossRef]

45. Zhang, X.; Yu, Y.; Zhang, N. Sustainable supply chain management under big data: A bibliometric analysis. J. Enterp. Inf. Manag. 2020. [CrossRef]

46. Sahoo, S. Big data analytics in manufacturing: A bibliometric analysis of research in the field of business management. Int. J. Prod. Res. 2021, 1-29. [CrossRef]

47. Pournader, M.; Shi, Y.; Seuring, S.; Koh, S.L. Blockchain applications in supply chains, transport and logistics: A systematic review of the literature. Int. J. Prod. Res. 2020, 58, 2063-2081. [CrossRef]

48. Aldrighetti, R.; Battini, D.; Ivanov, D.; Zennaro, I. Costs of resilience and disruptions in supply chain network design models: A review and future research directions. Int. J. Prod. Econ. 2021, 235, 108103. [CrossRef]

49. Bastian, M.; Heymann, S.; Jacomy, M. (Eds.) Gephi: An Open Source Software for Exploring and Manipulating Networks; AAAI Press: Palo Alto, CA, USA, 2009.

50. Persson, O.; Danell, R.; Schneider, J.W. How to use bibexcel for various types of bibliometric analysis. Celebrating Scholarly Communication Studies: A Festschrift for Olle Persson at his 60th Birthday. ISSI 2009, 5, 9-24.

51. Chen, C. CiteSpace II: Detecting and visualizing emerging trends and transient patterns in scientific literature. J. Am. Soc. Inf. Sci. Technol. 2006, 57, 359-377. [CrossRef] 
52. Thomas, J.; Harden, A. Methods for the thematic synthesis of qualitative research in systematic reviews. BMC Med. Res. Methodol. 2008, 8, 45. [CrossRef] [PubMed]

53. Shirowzhan, S.; Sepasgozar, S.M.E.; Edwards, D.J.; Li, H.; Wang, C. BIM compatibility and its differentiation with interoperability challenges as an innovation factor. Autom. Constr. 2020, 112, 103086. [CrossRef]

54. Leung, X.Y.; Sun, J.; Bai, B. Bibliometrics of social media research: A co-citation and co-word analysis. Int. J. Hosp. Manag. 2017, 66, 35-45. [CrossRef]

55. Chen, N.; Liu, W.; Bai, R.; Chen, A. Application of computational intelligence technologies in emergency management: A literature review. Artif. Intell. Rev. 2019, 52, 2131-2168. [CrossRef]

56. Sun, W.; Bocchini, P.; Davison, B.D. Applications of artificial intelligence for disaster management. Nat. Hazards 2020, 1-59. [CrossRef]

57. Baryannis, G.; Validi, S.; Dani, S.; Antoniou, G. Supply chain risk management and artificial intelligence: State of the art and future research directions. Int. J. Prod. Res. 2019, 57, 2179-2202. [CrossRef]

58. Cavalcante, I.M.; Frazzon, E.M.; Forcellini, F.A.; Ivanov, D. A supervised machine learning approach to data-driven simulation of resilient supplier selection in digital manufacturing. Int. J. Inf. Manag. 2019, 49, 86-97. [CrossRef]

59. Dong, S.; Yu, T.; Farahmand, H.; Mostafavi, A. Bayesian modeling of flood control networks for failure cascade characterization and vulnerability assessment. Comput.-Aided Civ. Inf. Eng. 2020, 35, 668-684. [CrossRef]

60. Gupta, R.; Tanwar, S.; Tyagi, S.; Kumar, N. Machine learning models for secure data analytics: A taxonomy and threat model. Comput. Commun. 2020, 153, 406-440. [CrossRef]

61. Li, R.; Tian, X.; Yu, L.; Kang, R. A systematic disturbance analysis method for resilience evaluation: A case study in material handling systems. Sustainability 2019, 11, 1447. [CrossRef]

62. Li, Y.; Chen, K.; Collignon, S.; Ivanov, D. Ripple effect in the supply chain network: Forward and backward disruption propagation, network health and firm vulnerability. Eur. J. Oper. Res. 2021, 291, 1117-1131. [CrossRef]

63. Manandhar, A.; Fischer, A.; Bradley, D.J.; Salehin, M.; Islam, M.S.; Hope, R.; Clifton, D.A. Machine learning to evaluate impacts of flood protection in Bangladesh, 1983-2014. Water 2020, 12, 483. [CrossRef]

64. Dick, K.; Russell, L.; Souley Dosso, Y.; Kwamena, F.; Green, J.R. Deep learning for critical infrastructure resilience. J. Inf. Syst. 2019, 25, 5019003. [CrossRef]

65. Jeble, S.; Kumari, S.; Venkatesh, V.G.; Singh, M. Influence of big data and predictive analytics and social capital on performance of humanitarian supply chain: Developing framework and future research directions. Benchmarking 2019, 27, 606-633. [CrossRef]

66. Akter, S.; Wamba, S.F. Big data and disaster management: A systematic review and agenda for future research. Ann. Oper. Res. 2019, 283, 939-959. [CrossRef]

67. Sarker, M.N.I.; Peng, Y.; Yiran, C.; Shouse, R.C. Disaster resilience through big data: Way to environmental sustainability. Int. J. Dis. Risk Reduc. 2020, 51, 101769. [CrossRef]

68. Masood, T.; So, E.; McFarlane, D. Disaster Management Operations-Big Data Analytics to Resilient Supply Networks. In Proceedings of the 24th EurOMA Conference, Edinburgh, UK, 1-5 July 2017.

69. Papadopoulos, T.; Gunasekaran, A.; Dubey, R.; Altay, N.; Childe, S.J.; Fosso-Wamba, S. The role of big data in explaining disaster resilience in supply chains for sustainability. J. Clean. Prod. 2017, 142, 1108-1118. [CrossRef]

70. Bui, T.-D.; Tsai, F.M.; Tseng, M.-L.; Tan, R.R.; Yu, K.; Lim, M.K. Sustainable supply chain management towards disruption and organizational ambidexterity: A data driven analysis. Sustain. Prod. Consum. 2021, 26, 373-410. [CrossRef]

71. Ivanov, D.; Dolgui, A. A digital supply chain twin for managing the disruption risks and resilience in the era of Industry 4.0. Prod. Plann. Control. 2020, 1-14. [CrossRef]

72. Shah, S.A.; Seker, D.Z.; Rathore, M.M.; Hameed, S.; Yahia, S.B.; Draheim, D. Towards disaster resilient smart cities: Can Internet of Things and big data analytics be the game changers? IEEE Access 2019, 7, 91885-91903. [CrossRef]

73. Singh, N. Developing business risk resilience through risk management infrastructure: The moderating role of big data analytics. Inf. Syst. Manag. 2020, 1-19. [CrossRef]

74. Mei, G.; Xu, N.; Qin, J.; Wang, B.; Qi, P. A Survey of Internet of Things (IoT) for Geohazard Prevention: Applications, technologies, and challenges. IEEE Int. Things J. 2020, 7, 4371-4386. [CrossRef]

75. Yang, J.; Hou, H.; Chen, Y.; Han, L. An Internet of Things based material delivery model for disaster management in libraries. Libr. Hi Tech 2019, 38, 181-194. [CrossRef]

76. Hou, H.; Yang, J.; Chen, Y.; Yu, M. A material delivery system built on Internet of Things and the role of libraries. Libr. Hi Tech. 2019, 38, 195-209. [CrossRef]

77. Xing, L. Reliability in Internet of Things: Current status and future perspectives. IEEE Internet Things J. 2020, 7, 6704-6721. [CrossRef]

78. Chen, H.Y.; Das, A.; Ivanov, D. Building resilience and managing post-disruption supply chain recovery: Lessons from the information and communication technology industry. Int. J. Inf. Manag. 2019, 49, 330-342. [CrossRef]

79. Chen, Y. Industrial information integration-A literature review 2006-2015. J. Ind. Inf. Integr. 2016, 2, 30-64. [CrossRef]

80. Kumar, A.; Rajalakshmi, K.; Jain, S.; Nayyar, A.; Abouhawwash, M. A novel heuristic simulation-optimization method for critical infrastructure in smart transportation systems. Int. J. Commun. Syst. 2020, 33. [CrossRef]

81. Sood, S.K. Bibliometric monitoring of research performance in ICT-based disaster management literature. Qual. Quant. 2021, $55,103-132$. 
82. Soyata, T.; Habibzadeh, H.; Ekenna, C.; Nussbaum, B.; Lozano, J. Smart city in crisis: Technology and policy concerns. Sustain. Cities Soc. 2019, 50. [CrossRef]

83. Yuan, Z.; Sun, C.; Wang, Y. Design for manufacture and assembly-oriented parametric design of prefabricated buildings. Autom Constr. 2018, 88, 13-22. [CrossRef]

84. Luo, L.; Liang, X.; Fang, C.; Wu, Z.; Wang, X.; Wang, Y. How to promote prefabricated building projects through Internet of Things? A game theory-based analysis. J. Clean. Prod. 2020, 276, 124325. [CrossRef]

85. Ghannad, P.; Lee, Y.-C.; Choi, J.O. Feasibility and implications of the modular construction approach for rapid post-disaster recovery. Int. J. Ind. Constr. 2020, 1, 64-75. [CrossRef]

86. Ghannad, P.; Lee, Y.-C.; Choi, J.O. Investigating stakeholders' perceptions of feasibility and implications of modular constructionbased post-disaster reconstruction. In Proceedings of the Modular and Offsite Construction (MOC) Summit Proceedings 2019, Banff, AB, Canada, 21-24 May 2019; pp. 504-513. [CrossRef]

87. Saeed, Z.O.; Almukhtar, A.; Salih, K. (Eds.) Construction Beyond War: Assessing Time and Cost of Prefabrication in Rebuilding Post-Disaster Cities; Saeed; IOP Publishing: Bristol, UK, 2021.

88. Yaacoub, J.-P.; Noura, H.N.; Salman, O.; Chehab, A. Robotics cyber security: Vulnerabilities, attacks, countermeasures, and recommendations. Int. J. Inf. Secur. 2021. [CrossRef] [PubMed]

89. Fuentes, R.; Chapman, T.; Cook, M.; Scanlan, J.; Li, Z.; Richardson, R.C. Briefing: UK-RAS white paper in robotics and autonomous systems for resilient infrastructure. Proc. Inst. Civ. Eng. -Smart Inf. Cons. 2017, 170, 72-79. [CrossRef]

90. Wagner, H.J.; Alvarez, M.; Groenewolt, A.; Menges, A. Towards digital automation flexibility in large-scale timber construction: Integrative robotic prefabrication and co-design of the BUGA Wood Pavilion. Constr. Robot. 2020, 4, 187-204. [CrossRef]

91. Nguyen, W.; Nof, S.Y. Collaborative response to disruption propagation (CRDP) in cyber-physical systems and complex networks. Decis. Support Syst. 2019, 117, 1-13. [CrossRef]

92. Green, A.; Dodson, K.; Woszczynski, A.B.; Easton, P. Responding to cybersecurity challenges: Securing vulnerable U.S. emergency alert systems. Commun. Assoc. Inf. Syst. 2020, 46, 187-208. [CrossRef]

93. Rasouli, M.R. Intelligent process-aware information systems to support agility in disaster relief operations: A survey of emerging approaches. Int. J. Prod. Res. 2019, 57, 1857-1872. [CrossRef]

94. Sarkheil, H.; Rad, M.H. (Eds.) 4D Electrical Resistivity Tomography Monitoring of Talesh Mahaleh-Rasht Coastal Aquifer Polluted by Caspian Seawater; European Association of Geoscientists \& Engineers: Turin, Italy, 2015.

95. Bosher, L.; Chmutina, K. Disaster Risk Reduction for The Built Environment; Wiley Online Library: Hoboken, NJ, USA, 2017.

96. Fernando, R.L.S. (Ed.) Artificial Intelligence and Disaster Management in Sri Lanka: Problems and Prospects; Springer: New York, NY, USA, 2020.

97. Mitsova, D.; Escaleras, M.; Sapat, A.; Esnard, A.-M.; Lamadrid, A.J. The effects of infrastructure service disruptions and socio-economic vulnerability on hurricane recovery. Sustainability 2019, 11, 516. [CrossRef]

98. Song, Y.; Wang, X.; Tan, Y.; Wu, P.; Sutrisna, M.; Cheng, J.; Hampson, K. Trends and opportunities of BIM-GIS integration in the architecture, engineering and construction industry: A review from a spatio-temporal statistical perspective. ISPRS Int. J. Geo-Inf. 2017, 6, 397. [CrossRef]

99. Moşteanu, N.R.; Faccia, A.; Cavaliere, L.P.L. Disaster Management, Digitalization and Financial Resources: Key Factors to Keep The Organization Ongoing. In Proceedings of the 4th International Conference on Cloud and Big Data Computing, ICCBDC 2020, Virtual, Online, UK, 26-28 August 2020.

100. Mottahedi, A.; Sereshki, F.; Ataei, M.; Qarahasanlou, A.N.; Barabadi, A. Resilience estimation of critical infrastructure systems: Application of expert judgment. Reliab. Eng. Syst. Saf. 2021, 215, 107849. [CrossRef]

101. Kamble, S.S.; Gunasekaran, A. Big data-driven supply chain performance measurement system: A review and framework for implementation. Int. J. Prod. Res. 2020, 58, 65-86. [CrossRef]

102. Bag, S.; Wood, L.C.; Xu, L.; Dhamija, P.; Kayikci, Y. Big data analytics as an operational excellence approach to enhance sustainable supply chain performance. Resour. Conserv. Recyc. 2020, 153, 104559. [CrossRef]

103. Ahmed, V.; Tezel, A.; Aziz, Z.; Sibley, M. The future of big data in facilities management: Opportunities and challenges. Facilities 2017, 35, 725-745. [CrossRef]

104. Inamdar, Z.; Raut, R.; Narwane, V.S.; Gardas, B.; Narkhede, B.; Sagnak, M. A systematic literature review with bibliometric analysis of big data analytics adoption from period 2014 to 2018. J. Enterp. Inf. Manag. 2020. [CrossRef]

105. van Westen, C.J. Remote sensing and GIS for natural hazards assessment and disaster risk management. Treatise Geomorphol. 2013, 3, 259-298.

106. Xiao, Y.; Huang, Q.; Wu, K. Understanding social media data for disaster management. Nat. Hazards 2015, 79, 1663-1679. [CrossRef]

107. Ghaffarian, S.; Kerle, N.; Filatova, T. Remote sensing-based proxies for urban disaster risk management and resilience: A review. Remote Sens. 2018, 10, 1760. [CrossRef]

108. UNISDR. Sharing Innovations to Improve Implementation and Reporting of the Sendai Framework for Disaster Risk Reduction; UNISDR: Geneva, Switzerland, 2016.

109. Giusto, D.; Iera, A.; Morabito, G.; Atzori, L. The Internet of Things: 20th Tyrrhenian Workshop on Digital Communications; Springer Science \& Business Media: Berlin, Germany, 2010.

110. Atzori, L.; Iera, A.; Morabito, G. The Internet of Things: A survey. Comput. Netw. 2010, 54, 2787-2805. [CrossRef] 
111. Gamil, Y.; Abdullah, M.A.; Abd Rahman, I.; Asad, M.M. Internet of Things in construction industry revolution 4.0. J. Eng. Des. Technol. 2020, 18. [CrossRef]

112. Malik, P.K.; Sharma, R.; Singh, R.; Gehlot, A.; Satapathy, S.C.; Alnumay, W.S. Industrial Internet of Things and its Applications in Industry 4.0: State of The Art. Comput. Commun. 2021, 166, 125-139. [CrossRef]

113. Al-Turjman, F. Cognitive routing protocol for disaster-inspired Internet of Things. Future Gener. Comput. Syst. 2019, 92, 1103-1115. [CrossRef]

114. Russell, L.; Goubran, R.; Kwamena, F.; Knoefel, F. Agile IoT for critical infrastructure resilience: Cross-modal sensing as part of a situational awareness approach. IEEE Int. Things J. 2018, 5, 4454-4465. [CrossRef]

115. Golpîra, H.; Khan, S.; Safaeipour, S. A review of logistics Internet-of-Things: Current trends and scope for future research. J. Ind. Infor. Integr. 2021, 22. [CrossRef]

116. Lizarralde, G.; Johnson, C. Myths and realities of prefabrication for post-disaster reconstruction. In Building Resilience Achieving Effective Post-Disaster Reconstruction; I-Rec: Latham, NY, USA, 2008.

117. Bertram, N.; Fuchs, S.; Mischke, J.; Palter, R.; Strube, G.; Woetzel, J. Modular Construction: From Projects to Products; McKinsey \& Company: Brussels, Belgium, 2019; pp. 1-34, Capital Projects \& Infrastructure.

118. Alvanchi, A.; Azimi, R.; Lee, S.; AbouRizk, S.M.; Zubick, P. Off-site construction planning using discrete event simulation. J. Archit. Eng. 2012, 18, 114-122. [CrossRef]

119. Innella, F.; Arashpour, M.; Bai, Y. Lean methodologies and techniques for modular construction: Chronological and critical review. J. Constr. Eng. Manag. 2019, 145, 4019076. [CrossRef]

120. Blismas, N. Off-site Manufacture in Australia: Current State and Future Directions; CRC for Construction Innovation: Queensland, Australia, 2007.

121. Hong, J.; Shen, G.Q.; Li, Z.; Zhang, B.; Zhang, W. Barriers to promoting prefabricated construction in China: A cost-benefit analysis. J. Clean. Prod. 2018, 172, 649-660. [CrossRef]

122. Murphy, R.R. Disaster Robotics; MIT Press: Cambridge, MA, USA, 2014.

123. Rad, M.H.; Sarkheil, H.; Khojastehpour, R. (Eds.) Analysing Water Use Efficiency and Productivity in Iran's Metropolises; Thomas Telford Ltd.: London, UK, 2019. [CrossRef]

124. Norouzalizadeh, G.R.; Habibi, R.M. Improving energy consumption in building products using life cycle assessment and energy analysis. Asian J. Civ. Eng. (Build. Hous.) 2016, 17, 443-457.

125. Pan, Y.; Zhang, L. Roles of artificial intelligence in construction engineering and management: A critical review and future trends. Autom. Constr. 2021, 122, 103517. [CrossRef]

126. Winkelhaus, S.; Grosse, E.H. Logistics 4.0: A systematic review towards a new logistics system. Int. J. Prod. Res. 2020, 58, 18-43. [CrossRef]

127. Lee, E.A. (Ed.) Cyber Physical Systems: Design Challenges; IEEE: Washington, DC, USA, 2008.

128. Bonci, A.; Carbonari, A.; Cucchiarelli, A.; Messi, L.; Pirani, M.; Vaccarini, M. A cyber-physical system approach for building efficiency monitoring. Autom. Constr. 2019, 102, 68-85. [CrossRef]

129. Lei, Y.; Rao, Y.; Wu, J.; Lin, C.-H. BIM based cyber-physical systems for intelligent disaster prevention. J. Ind. Infor. Integr. 2020, 20, 100171. [CrossRef] 